\title{
The Way Forward in Mindfulness and Sustainability: a Critical Review and Research Agenda
}

\author{
Ute B. Thiermann ${ }^{1}$ (D) $\cdot$ William R. Sheate ${ }^{1}$
}

Received: 8 January 2020 / Accepted: 7 June 2020 / Published online: 2 July 2020

(C) The Author(s) 2020

\begin{abstract}
The ecological crisis demands new strategies to rapidly transform our society into a more sustainable one. A growing amount of research points towards the potential of mindfulness to help transform people's motivations for sustainability. This article reviews 30 years of research in mindfulness and sustainability and disentangles theoretical knowledge from empirical evidence. We identified six leading theoretical links between mindfulness and sustainability which find backing in empirical work: reduced automaticity, enhanced health and subjective well-being, greater connectedness with nature, improved pro-sociality, recognition of intrinsic values and openness to new experiences. Many of the studies involve considerable methodological caveats, most importantly a lack of mindfulness practice indicators and environmental impact measures. To reach the point where policy makers could embrace mindfulness-based policies to promote societal well-being and sustainability, the research must go beyond the present focus on correlative research. The proof of causality posits the greatest challenge for the next decade of research. Inspired by principles from policy evaluation, we propose a research agenda that offers direction for collaborative efforts and innovative interdisciplinary study designs in a logical model: (how) does the practice of mindfulness contribute to individual behaviour change and (how) does this individual change translate into societal change?
\end{abstract}

Keywords Mindfulness $\cdot$ Methods $\cdot$ Sustainability $\cdot$ Environment $\cdot$ Pro-environmental behaviours $\cdot$ Nature connectedness

\section{Introduction}

With the ecological crisis progressing and the impacts of climate change becoming more and more tangible every year, the search for ways to render our society more sustainable is reaching unprecedented levels of urgency. This includes the growing awareness that it will need the support of people to resolve this people-made crisis (Clayton et al. 2015, 2016; Bain et al. 2016; Beckage et al. 2018). Due to the deeply rooted origin of human cultures and behaviours, it is becoming increasingly evident that it needs strategies that affect people at the very core of their personality and change

Electronic supplementary material The online version of this article (https://doi.org/10.1007/s41465-020-00180-6) contains supplementary material, which is available to authorized users.

Ute B. Thiermann

ute.thiermann15@imperial.ac.uk

1 Centre for Environmental Policy, Imperial College London, 16-18 Prince's Gardens, Weeks Building, London SW7 1NE, UK some of their worldviews, values and beliefs (O'Brien 2018; Ives et al. 2019).

Over the course of the past 20 years, several authors are now paying attention to the role of contemplative science to help in this transformation of the inner sphere of human beings (Wamsler 2019). As a result of the spread of mainstream mindfulness into various sectors of society and the successes of meditation research, there also is a growing base of researchers from diverse fields who started exploring how mindfulness affects sustainability and pro-environmental behaviour (PEB) (Jacob et al. 2009; Ericson et al. 2014; Siqueira and Pitassi 2016; Fischer et al. 2017; Wamsler et al. 2017; Wamsler 2018). Enthusiastic about first research showing the potential of mindfulness to play a role in the sustainability transformation, some moved on to advocate mindfulness as a potential element in the search for more sustainable pathways. Other researchers warn of the danger to understand mindfulness as a panacea strategy for all ills of our society (Schmidt 2016; Creswell 2017; Kabat-Zinn 2017; Van Dam et al. 2018; Singer and Engert 2019). Regarding the ecological crisis, there seems to be an implicit hope that mindfulness could become a political strategy with a 'double' or even 'triple' 
dividend (Ericson et al. 2014; Dhandra 2019). The message is that 'if the positive effects prove large enough, this could be promoted as a public policy, not only because of sustainability issues, but also because of its effects on well-being and prosocial behaviour' (Ericson et al. 2014, p. 77). But how much do we know about the relationship between mindfulness, PEB and the transition to a more sustainable society? And does our knowledge as of today justify the claim for a public investment in the promotion of mindfulness programs for the sake of sustainability?

The aim of this review is to undertake a critical evaluation of the existing research and to draw out a future research agenda that could lead to answering the questions policy makers might have before any investments can be justified. In the second section, we present the methodology for our review of the mindfulness and sustainability literature. The third section outlines the historical evolution of the topic since its first mentioning in 1999 until 2009. The next two sections focus on the increasing volume of studies published between 2010 and 2020, with the objective to disentangle theoretical work (fourth section) from empirical evidence for the six main theoretical arguments linking mindfulness and sustainable behaviours (fifth section). The sixth section identifies the major methodological issues of the mindfulness and sustainability research, including a discussion of the challenge to prove causality between the concepts. Based on the review and methodological critique, we propose a research agenda for the years to come in the seventh section. Section eight concludes with a positive outlook for the mindfulness and sustainability research.

\section{Methodology}

This work is based on a traditional literature review which integrates several key principles of a systematic literature review, to improve objectivity and transparency and avoid biases in the selection of studies (Haddaway et al. 2015). The first step of this review was a keyword search for the word combination 'mindfulness AND sustainability' in the three databases Google Scholar, Web of Science, and Scopus. These have been proven stable in coverage and are adequate for cross-disciplinary comparisons (Harzing and Alakangas 2016). Google scholar, while returning an extensive list of 29,400 hits (from which most were irrelevant to this research), has the advantage to also include academic books and grey literature in the results. We screened the Google scholar search results up to page 30 , a few pages after that displaying no further relevant findings.

All databases yielded a large proportion of articles outside the subject area, so that search results had to be screened manually to find the relevant publications. In total, a list of 66 publications were identified; from which 50 are peer- reviewed journal articles, 6 are academic book chapters and 10 are grey literature such as reports and conference proceedings (see supplementary material for list of all 66 publications). Figure 1 presents the total number of selected results by year, showing a general trend of research in the area interfacing mindfulness and sustainability.

Departing from this list of peer-reviewed articles, we applied the snowballing method to include further related work from the articles' reference lists. We also carried out additional keyword searches with a variety of keyword combinations to identify specialized studies on the theoretical key arguments presented in the 'Empirical Evidence of Main Theoretical Links' section.

This review focuses on peer-reviewed journal publications and books from academic publishers, released over a 20-year period since the first publications in 1999 up to 2020 . Furthermore, in bounding the scope of this article, content is focussed to 'meditative mindfulness' (Hart et al. 2013) of the John Kabat-Zinn tradition and pays less attention to studies that have incorporated the 'creative mindfulness' (Hart et al. 2013) concept by Langer (examples of such studies are Wang et al. 2016, 2019; Tang et al. 2017; Helm and Subramaniam 2019). Meditative mindfulness has dominated the literature regarding mindfulness and sustainability and also involves a distinct approach to designing interventions and measuring mindfulness. Despite this focus, we emphasize that the concepts do overlap significantly and some of our observations may apply to both. Finally, our article centres around ecological sustainability and only refers briefly to social sustainability in the 'Societal Change' section.

\section{The Beginnings}

The first academic and peer-reviewed journal article referring to the term 'mindfulness' in combination with the term 'sustainability' was published in 1999, when Brinkerhoff and Jacob were inspired by the theoretical stance of deep ecologists in the 1990s:

In order to prevent a generalized ecosystems collapse before the mid-twenty-first century, humankind must experience a change in consciousness comparable in its intensity and comprehensiveness to the cultural shifts accompanying the agricultural and industrial revolution. [...] This change in consciousness centres on healing humankind's alienation from nature in terms of a dualistic subject/object split that permits violence directed towards the earth, justified by the drive for material accumulation. (Brinkerhoff and Jacob 1999: p. 557)

Deep ecologists turned towards Eastern religions and meditation as approaches for overcoming the separation 
Fig. 1 A keyword search of the terms 'mindfulness AND sustainability' returned 66 peerreviewed journal articles, academic books and grey literature, published between 1999 and 2020. Note: subject-relevant articles were selected manually and the numbers for 2020 (light grey) reflect publications up to April 2020
Peer-reviewed journal articles and grey literature on

"mindfulness AND sustainability" by year

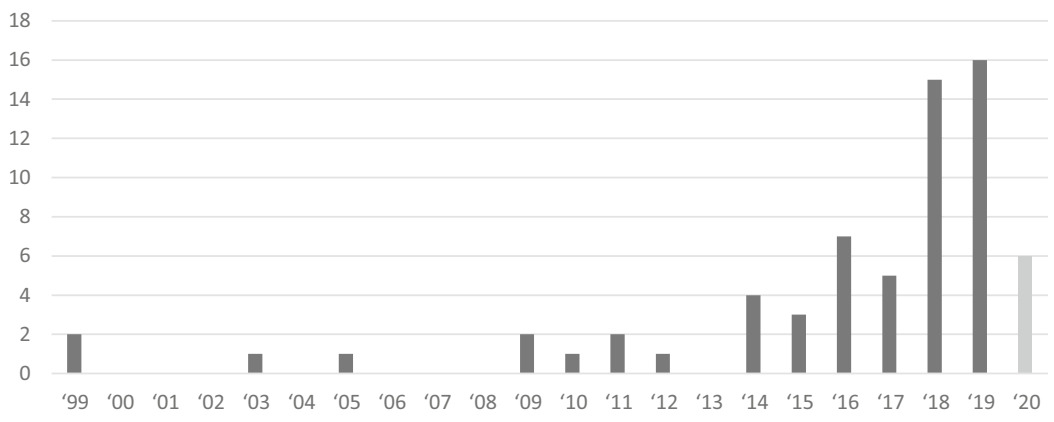

between humans and nature and therefore to cease environmental destruction. Brinkerhoff and Jacob (1999) used this theoretical groundwork to build their empirical research design to study mindfulness and sustainability. Their publication pioneered the explicit measuring of mindfulness using scaling criteria in their survey of over 500 back-to-thelanders in rural USA. In their comparison of secular mindfulness as a quasi-religion against religiosity, they could show that mindfulness was associated with higher quality of life factors as well as with ecological values. Contrary to this, adopters of organized religion did not show the same potential for a non-dualistic expression of consciousness. In a second publication in the same year, the authors reaffirmed their hypothesis that mindfulness might contribute to sustainability by promoting a non-materialistic well-being concept (Jacob and Brinkerhoff 1999).

A few years later in a theoretical book chapter on sustainable consumption, mindfulness again was hypothesised to serve as an antidote to the destructive results of consumerism (Rosenberg 2004). In this chapter, the two mechanisms explaining this effect are based on the observation that mindfulness increases awareness. With heightened levels of awareness, Rosenberg (2004) theorizes that automatic behavioural patterns reduce as well as more intrinsic fulfilment and interrelatedness with others emerge (Rosenberg 2004). Cognisant of the lack of empirical evidence to support these statements, Rosenberg (2004) concluded by drafting an empirical agenda to explore this unresearched field. One year later, a survey of two different samples, 200 students and 250 adults, confirmed that intrinsic value orientation and mindfulness are correlated with subjective well-being and pro-environmental behaviour (PEB) indicators (Brown and Kasser 2005). Brown and Kasser's (2005) work feds into the growing understanding that, contrary to popular beliefs, ecological behaviours can promote well-being rather than deteriorating it (Venhoeven et al. 2013).

From the year 2009 onwards, 10 years after the first mentioning of the link between mindfulness and sustainability, yearly increasing numbers of publications provide theoretical accounts and empirical evidence for their connection. As it is often the case with research in its infancy stages, the lack of resources and knowledge on the topic resulted in many methodological issues of the early studies. However, these pieces of pioneer work have built the foundation for an ever-growing trend of studies pointing repeatedly towards the understanding that mindfulness could be linked to improved environmental awareness and behaviours and may support a social transformation to a more sustainable society. In the following, this article moves on to report and synthesize publications of the last decade, from 2009 to 2019.

\section{Theoretical Foundations}

As a Vietnamese Monk of the Zen Buddhist tradition, Thich Nhat Hanh escaped to the West at the turbulent times of the Vietnam War where he founded the movement of Engaged Buddhism. Thich Nhat Hanh rose to become a spiritual leader in the West, advocating the importance of mindfulness to overcome many challenges of the modern society (Weisbaum 2017). He suggests that mindfulness could help solving the ecological crisis:

There is a revolution that needs to happen, and it starts from inside each one of us. When we change the way we see the world, when we realize that we and the Earth are one and we begin to live with mindfulness, our own suffering will start to ease. When we're no longer overwhelmed by our own suffering, we will have the compassion and understanding to treat the Earth with love and respect. Restoring balance to ourselves, we can begin the work of restoring balance to the Earth. [...] There is no difference between healing the planet and healing ourselves. (Hanh 2013, pp. 56-57)

Thich Nhat Hanh gained these insights through life-long dedication to the practice of mindfulness and compassion. In its simplicity, however, this paragraph points towards a 
realization that also can be observed in academic circles: for a successful transition towards a sustainable society, it is crucial to encourage transformation of the inner dimensions of individuals (O'Brien 2018; Wamsler 2018, 2019; Ives et al. 2019). This includes the restoration of the relational capacities inherent to human nature, which also extend to the relatedness with the natural environment (Thiermann and Sheate 2020). To enable individuals to become truly sustainable, the intellectual dominance of mind over body, head over heart and person over world has to be brought to new balance (Livingstone 2019).

\section{Individual Behaviour Change}

Ericson et al. (2014) were the first to provide a comprehensive review of the literature on mindfulness and sustainability, identifying and organizing some of the theoretical key arguments for a potential link between the concepts. They advocate that because mindfulness has shown to be associated with increased subjective well-being, pro-social behaviours, and awareness of one's intrinsic values, these qualities in turn might help to strengthen PEB (see Fig. 2). Ericson et al. (2014) also argue that emotional awareness and self-regulation, as well as greater attention, could possibly contribute to the disruption of unsustainable habits.

The overcoming of harmful habits also is at the centre of the theory of change presented by Bahl et al. (2016), whose model is inspired by Buddhist interpretations of the processes involved in creating mindful insight. They reason that because mindfulness has been found to heighten levels of attention and non-judgmental acceptance, it increases an individual's awareness of their inner and outer world, which in turn creates deep understanding of one's psychological conditioning. Based on these personal insights into the origin and functionality of one's habits, Bahl et al. (2016) advocate that the attachment to those is reduced and the individuals becomes freed from unreflected automatism and habits. They argue that the final stage of this process creates the potential for widespread transformation regarding the well-being of consumers and society, as well as the environment (see Fig. 3).

The theoretical models linking mindfulness and PEB so far have evolved in disconnect from the mainstream models on proenvironmental behaviours developed by environmental psychologists. The two-pathway model of pro-environmental behaviours (Fig. 4) builds a bridge between the two, by reinforcing how mindfulness could serve as an experiential strategy that strengthens both the normative as well as the relational aspects of pro-environmental behaviours (Thiermann and Sheate 2020).

The two-pathway model is embedded in the wider framework of self-determination theory and applies an eudemonic view on personal well-being, therefore communicating with those who see mindfulness as a way to engage with life in a more meaningful way and to satisfy basic psychological needs (Ryan and Deci 2008; Ryan et al. 2008; Garland et al. 2015; Kasser 2017; Hunecke and Richter 2019).

\section{Societal Change}

While the above-mentioned theoretical models focus on the processes by which mindfulness might contribute to transformation on the individual level, Wamsler et al. (2017) offer a framework which emphasizes how changes on the individual level can radiate outwards to promote changes at all other levels of society. The framework for contemplative scientific inquiry, practice and education in sustainability systematizes the various interlinkages between mindfulness and sustainability on all societal levels, from individual to global (see Fig. 5).

Similarly to the above statement by Thich Nhat Hanh, this framework is anchored in the understanding that the subjective well-being of the individual is mirrored by collective-planetary well-being and vice versa and that several benefits of mindfulness mediate between both poles of well-being. The framework carries several of the theoretical aspects covered by the models above,
Fig. 2 Hypothesised relationships between mindfulness, values/empathy/ compassion, well-being and sustainable behaviour (Ericson et al. 2014)

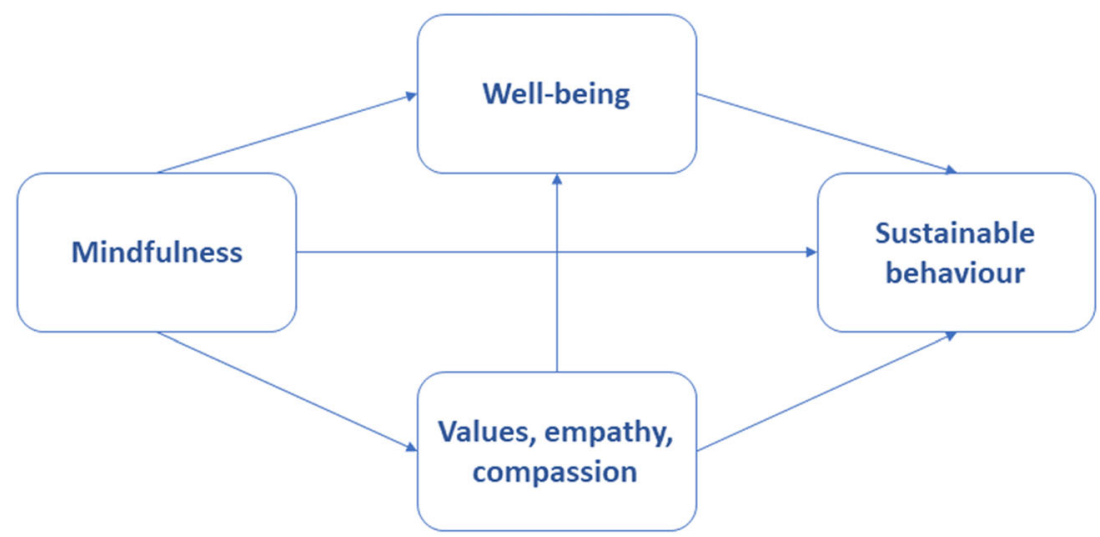


Fig. 3 The transformative potential of mindful consumption based on the process of mindful insight (Bahl et al. 2016)

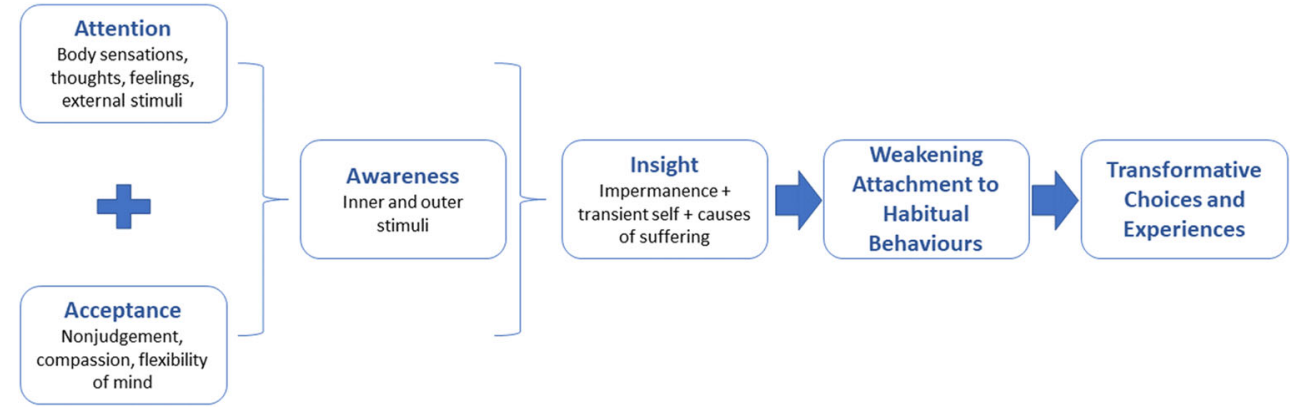

but also adds more elements such as physical health, flexibility to respond to and adapt to environmental change, connectedness with nature and interrelatedness with others, as well as social activism as a form of altruistic values in action. The framework envisions that mindfulness might be an inner capacity that can support a shift away from reactiveness towards wise action for sustainability. In line with this framework, which is based on both theoretical as well as empirical work in the form of experimental learning labs, Wamsler et al. (2017) advocate that it is crucial for sustainability practitioners to also consider inner dimensions of sustainability, such as mindfulness. This observation led the authors to pioneer contemplative and mindfulness-based elements as part of the educational programme for sustainability master students at Lund University in Sweden and to advocate a the spread of contemplative practices in mainstream education and education for sustainable development (Wamsler et al. 2017; Frank et al. 2019a; Wamsler 2019, 2020).

The observation that mindfulness may potentially radiate into organizations and public policy making has also been made by other authors. Siqueira and Pitassi (2016) argue that the impact from mindfulness can be extended into organizations by promoting creative leadership and sustainability- oriented innovations, particularly if taught with a more ethically informed view of mindfulness. Commonly, organizational mindfulness literature regarding sustainability has been dominated by those studying mindfulness in the context of emotional intelligence (Ciarrochi and Godsell 2013) and those inquiring about 'creative mindfulness' and social sustainability issues such as social justice, poverty reduction, livelihood and well-being (Becke 2014; Vihari and Rao 2017; Mäkiniemi and Heikkilä-Tammi 2018; Ndubisi et al. 2019; Sajjad and Shahbaz 2020). Furthermore, recently, researchers formalized the connections between 'meditative mindfulness' and social sustainability via the integrative mindfulness-social sustainability framework (Sajjad and Shahbaz 2020).

Meditative mindfulness has already found its way into the political realm, prompting political scientists to study its influence on politics (Ferguson 2016). A group of civil servants from the Welsh Government participated in a participatory action research to develop a 'Mindfulness, Behaviour Change and Engagement in Public Policy' programme (Pykett et al. 2016). On a national level, the British All-Party Parliamentary Group on Mindfulness enables politicians from both the Houses of Commons and Lords to collaboratively attend 8-week mindfulness courses. The group founded the Mindfulness Initiative, a network of mindfulness scientists and practitioners providing policy guidelines for the

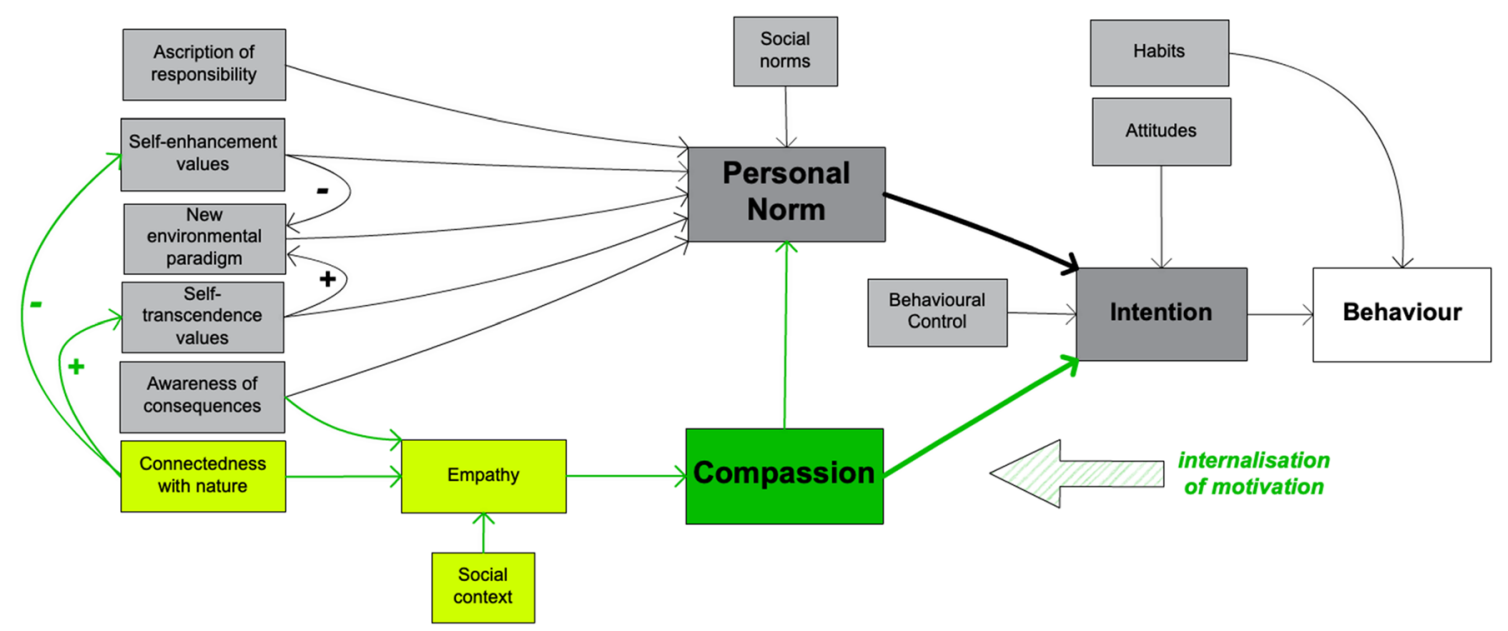

Fig. 4 The two-pathway model of PEB. Mindfulness practice is seen as an experiential strategy that could reinforce the relational pathway (green) of proenvironmental behaviours (Thiermann and Sheate 2020) 
Fig. 5 Framework for contemplative scientific inquiry, practice and education in sustainability (Wamsler et al. 2017)

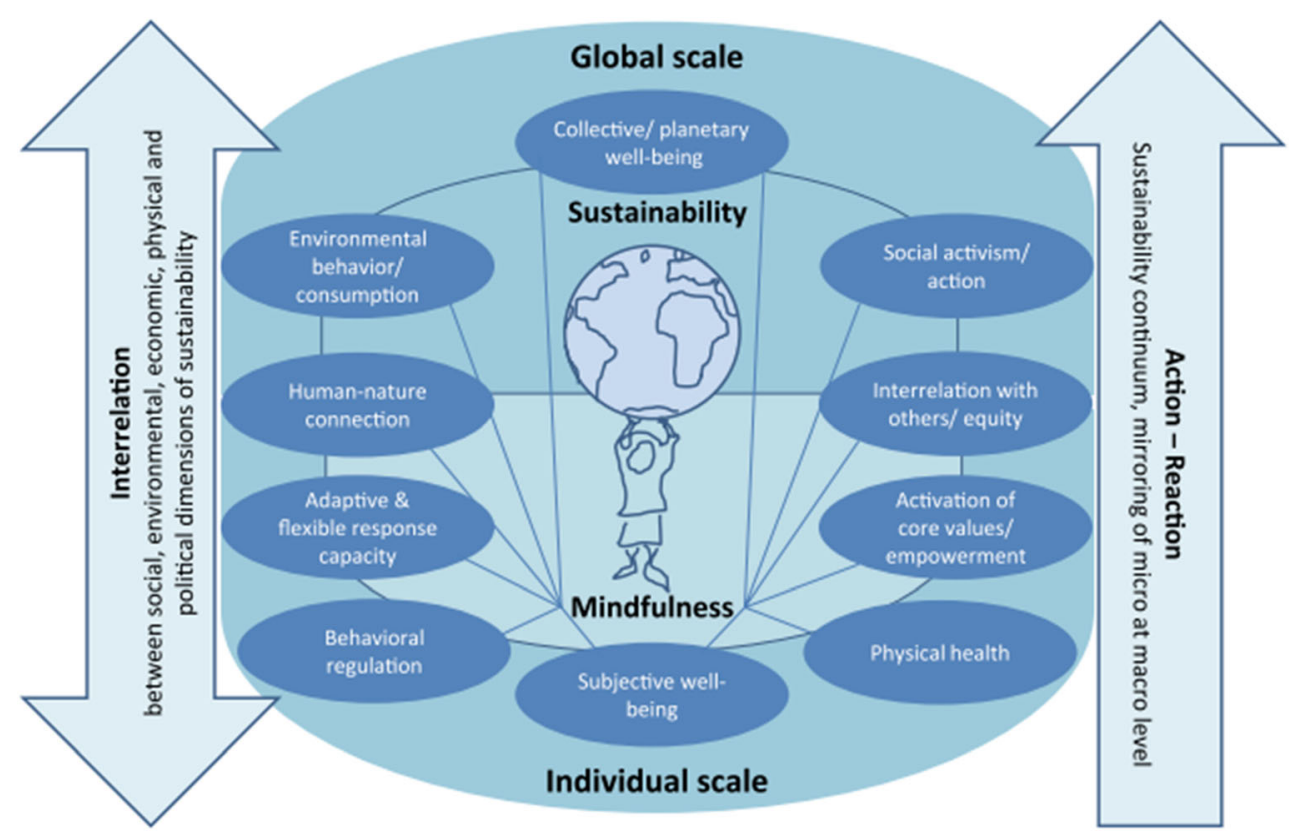

implementation of mindfulness in different public policy areas, such as health, education, business and the criminal system (MAPPG 2015). Meanwhile, more than 10 other countries are following with similar initiatives, striving to build a global initiative that advocates mindfulness as a tool for future-oriented policy making (Kabat-Zinn 2017; Bristow 2018).

\section{Empirical Evidence of Main Theoretical Links}

It is one of the caveats of the mindfulness and sustainability research that theoretical work often stands alone without empirical proof of the theoretical assumptions. The publications mentioned in the previous section base their models on a combination of general mindfulness literature and the broader sustainability literature, with reference to only a few studies explicitly measuring the hypothesised effects between mindfulness and PEB. With the objective to complement the review of the theoretical work with empirical evidence, we now move on to present findings from the predominantly quantitative studies in the field. We distilled six key arguments for the relationship between mindfulness and PEB on the individual level:

1. Increased awareness

2. Improved personal health and subjective well-being

3. Higher levels of connectedness with nature

4. Stronger pro-social tendencies such altruism, compassion and empathy

5. Stronger intrinsic values and ethical decision-making
6. Greater openness to new experiences

These statements provide the logical structure for the following section. The aim is to provide a summary of the empirical work backing these arguments, prior to a methodological critique in the following section. Whenever possible, the sections concentrate on studies that intended to contribute to the knowledge on mindfulness and sustainability.

\section{Awareness}

The force of habits is a significant barrier to a long-term change of environmental behaviours, particularly when unsustainable behaviours are based on unattended emotional impulses (Kollmuss and Agyeman 2002; Klöckner and Verplanken 2019). Mindfulness has been associated with a reduction in automatic and impulsive behaviours, due to its tendency to help individuals to observe their internal and external experiences and to act with more awareness (Baer et al. 2006). These processes of increased awareness towards internal and external experiences and greater ability to act with awareness support better emotion regulation (Chambers et al. 2009; Hölzel et al. 2011). Several studies showed the connection between these mechanisms of mindfulness and PEB.

An early study regarding the influence of the different facets of mindfulness on sustainable behaviour was carried out on a small sample of 100 visitors to a sustainability expo (Amel et al., 2009). Amel et al. (2009) ran simple regression analyses on a mindfulness scale and a green behaviour scale and found that the mindfulness facet acting with awareness, which reflects the capacity to pay full attention on one's 
actions as opposed to acting automatically, was significantly positively correlated with green behaviours. While Amel et al. (2009) did not find a meaningful relationship between the capacity to observe internal and external stimuli and the desired behaviours, two recent survey-based studies with mindfulness practitioners and non-practitioners in Germany identified the mindfulness facet observe as the strongest predictor of their selected indicators sustainable and organic food consumption (Hunecke and Richter 2019; Richter and Hunecke 2020). They also discovered a weak positive correlation between acting with awareness and sustainable food consumption, much of which was mediated by the respondents' capacity to engage in the construction of meaning and personal norms (Hunecke and Richter 2019). Both studies focused on possible pathways of action between dispositional mindfulness and sustainable diet behaviours, thereby reinforcing their distal relationship and the necessity to analyse mindfulness in combination with other important predictors of ecological behaviour.

Regarding impulsive buying behaviours, researchers demonstrated that higher levels of dispositional mindfulness were associated with a reduction in compulsive behaviours in a sample of 320 students from India (Park and Dhandra 2017). While not specifying between the different facets of mindfulness, Park and Dhandra (2017) discovered that emotional intelligence, particularly in its aspects of emotion regulation, almost fully mediated this relationship. This is also reflected in Barbaro and Pickett's (2016) findings that the mindfulness facet nonreactivity, the refraining from impulsive reactions to experience, is significantly correlated with pro-environmental behaviour. In one of the few qualitative studies in the field, Armstrong (2012) showed that the participation in a mindfulness intervention helped six compulsive consumers to reduce their addiction, due to improved increased awareness of thoughts, emotional regulation, self-acceptance and well-being. Generally, a qualitative project showed that the positive effect of mindfulness training on students' ability for introspection also appeared to contribute to the acquiring of key competencies in higher education for sustainable consumption (Frank et al. 2019b).

\section{Personal Health and Subjective Well-Being}

Since its beginnings, the mindfulness and sustainability narrative has been intimately connected with the concept of personal well-being (see 'The Beginnings' section). Several studies show a correlation between mindfulness, sustainability, personal health and subjective well-being. Researchers found that in two different student samples from a German university, healthier lifestyles partly mediated the positive relationship between mindful awareness of present experience and ecological behaviours (Geiger et al. 2018). In an analysis of the mindfulness facets, the researchers also discovered that increased awareness of bodily experiences and the external environment had the strongest association with both health and ecological behaviours. Several studies and metaanalyses have evidenced the positive effects of mindfulness on personal well-being (Brown and Ryan 2003; Brown et al. 2007; Carmody and Baer 2008; Keng et al. 2011; Goyal et al. 2014). At the same time, there is rising awareness that individuals with higher levels of well-being are more likely to also maintain a more sustainable lifestyle (Brown and Kasser 2005; Corral-Verdugo et al. 2011; Corral Verdugo 2012; Kasser 2017).

Some researchers explicitly studied the interconnections between mindfulness, personal well-being and PEB. One such study was carried out with over 800 Buddhist practitioners in California who engage in regular meditation practices as well as claim to have a commitment to an ecological lifestyle (Jacob et al. 2009). In this sample, multiple regressions resulted in the observation that both the level of PEB as well as mindfulness experience significantly predicted subjective well-being. Jacob et al. (2009) also showed that the level of meditation experience helped to explain the variance in subjective well-being. In another survey with 420 respondents from an Indian University, dispositional mindfulness was associated with more sustainable consumption patterns and increased life satisfaction (Dhandra 2019). Another aspect often mentioned as pivotal for personal well-being is a high level of self-compassion, which has seen increases after mindfulness training (Neff et al. 2007). Werner et al. (2020) found that a supportive mindset, marked by the ability to decentre from thoughts and cultivate self-compassion, is positively associated with improved PEB, dietary awareness and informed food choice.

\section{Connectedness with Nature}

Connectedness with nature (CWN) has grown into an important concept in environmental psychology and is defined as 'a stable state of consciousness comprising symbiotic cognitive, affective, and experiential traits that reflect, through consistent attitudes and behaviours, a sustained awareness of the interrelatedness between one's self and the rest of nature' (Zylstra et al. 2014). Confirmed in a meta-analysis of 37 samples $(n=$ 13,237), CWN has a strong positive association with individual performance in PEB and other conservation activities (Whitburn et al. 2019). More recently, several studies have consistently revealed a positive correlation between mindfulness and CWN, which also was confirmed in a meta-analytical study (Schutte and Malouff 2018). In this meta-analysis of 12 samples $(n=2435)$, Schutte and Malouff (2018) found an overall weighted effect size of $r=0.25$ and reveal that the strength of the relationship depended on the type of mindfulness scale applied in the studies. They also observed that the nature of the relationship between mindfulness and CWN might be reciprocal and bi-directional. 
While engagement in a mindfulness exercise has been discovered to improve CWN scores (Aspy and Proeve 2017), spending time in nature also showed a positive correlation with levels of CWN (Hamann and Ivtzan 2016). The strongest boost in CWN was found when nature experience was combined with mindfulness meditation (Unsworth et al. 2016; Djernis et al. 2019). In a meta-analysis of nature-based mindfulness trainings, Djernis et al. (2019) showed that the effect sizes for increases in CWN were larger when the mindfulness interventions had been implemented in wild nature as opposed to cultured green spaces.

Some studies go a step further and analyse the relationship between mindfulness, CWN and a third factor such as wellbeing or PEB (Howell et al. 2011; Barbaro and Pickett 2016). In two surveys with samples of approximately 450 and 275 psychology students, Howell et al. (2011) not only discovered significant positive associations between mindfulness, CWN and well-being indicators but also revealed that the three factors are significantly interrelated. Barbaro and Pickett (2016) conducted one survey with a sample of 360 students and another with almost 300 Mechanical Turk respondents. They showed that respondents with higher levels of mindfulness showed significantly more frequent engagement in PEB. They also found that this relationship between mindfulness and PEB was partially mediated by CWN. Both Barbaro and Pickett (2016) as well as Howell et al. (2011) present evidence for the mindfulness facet observing as the strongest predictor of a relationship between mindfulness and CWN. These authors assume that to experience emotions such as awe and wonder with the natural environment, one needs to slow down and actively pay attention to their environment.

Feelings of connectedness can expand beyond the natural world and involve a sense of connectedness with the universe and all beings. For example, a study with almost 1000 USAmerican students revealed that the positive association between dispositional mindfulness and psychological wellbeing was partly mediated by selflessness as an expression of the respondents' sense of interconnectedness with the social and natural world, and the universe (Hanley et al. 2017). This sense of greater interconnectedness sometimes is interpreted as an aspect of personal spirituality and might tend to be overlooked in studies about mindfulness and sustainability (Werner et al. 2020). In a study with more than 1200 adults in the USA and India, Werner et al. (2020) explored both mindfulness and spirituality as constructs involved in PEB and sustainable food decisions. They established that spirituality and mindfulness are indeed independent constructs, but that some spirituality traits might overlap with aspects from mindfulness, such as the awareness of the external environment and nature. Werner et al. (2020) also identify that natural spirituality, as lived in daily activities and the contact with nature, is associated with more sustainable dietary behaviours.
Despite this considerable amount of research investigating the correlational effects between mindfulness and CWN, there is a lack of longitudinal and experimental studies that would support a causal interpretation of their connection.

\section{Pro-sociality: Altruism, Compassion and Empathy}

Sustainability challenges often involve more than just an environmental problem. They also imply questions regarding social justice, such as, what is a fair use of our public goods and what would be a just distribution of the negative impacts from environmental destruction. One such pressing example of social inequality is the distribution of the health effects associated with climate change, which mostly affect the poor and vulnerable sections of the global society (Costello et al. 2009). Similar to the situation described in the article The tragedy of the commons (Hardin 1968), the management of environmental resources very often involve social dilemmas, power inequalities and competing motives such as greed, efficiency and fairness (von Borgstede et al. 2018). Finding answers to those social aspects are pivotal to solve our wicked problem of sustainability. Tendencies to perform PEB are often interlinked with pro-social or altruistic inclinations, which together can be described as universalist motivations to protect the welfare of all people and nature (de Groot and Thøgersen 2018). The ability to connect with others and to extend feelings of empathy and compassion to far-away communities and nun-human life is therefore assumed to be an important predictor for more ecological lifestyles (Tam 2013; Pfattheicher et al. 2016). Several authors have hypothesized that mindfulness might be associated with improved PEB because it strengthens pro-social tendencies such as empathy, compassion and altruism (Ericson et al. 2014; Fischer et al. 2017; Thiermann and Sheate 2020).

However, reviews regarding the effect of mindfulness on pro-sociality variables show varying results. Two metaanalyses on the topic published in the same year, however, come to differing conclusions (Donald et al. 2018; Kreplin et al. 2018. Donald et al. (2018) analysed 31 studies with 17,241 participants, of which 12 studies were correlational and 21 were intervention studies. Kreplin et al. (2018) reviewed 22 intervention studies with 1685 participants while also assessing the quality of those. Even though both metaanalyses review the same subject, they only share a few $(<5)$ intervention studies in their analysis pools. This could be explained by the fact that Kreplin et al. (2018) focussed on studies that measure the effect of mindfulness on predictors of pro-sociality, such as self-compassion, empathy or the inclination for prejudice, while Donald et al. (2018) reviewed studies that assessed pro-social behaviours directly, measured by self-report or other-report. Despite confirming that meditation was associated with a moderate increase in pro-sociality, particularly compassion and empathy, Kreplin et al. (2018) 
drew rather sceptical conclusions as they criticized several methodological weaknesses and the interventions' subjectivity to bias. Donald et al. (2018) observed that mindfulness interventions resulted in a medium-sized effect on pro-social behaviours. Their analysis of correlational studies returned a medium to large effect size for the association between dispositional mindfulness and pro-social behaviours. Donald et al. (2018) also discuss methodological issues of the interventions but conclude in a positive sense that mindfulness seems to promote ethical and cooperative behaviours with both known and unknown others, mediated via higher empathetic concern, emotion regulation and positive affect.

None of the two meta-analyses included the ReSource project which was performed over a period of 10 months in Germany and stands out in methodological rigour. A large sample of over 300 adults participated in this randomized control trial which separately assessed the effects of three different training modules which commonly are taught simultaneously in conventional mindfulness interventions. The three modules, displayed in Fig. 6, were taught in different orders to three groups of participants and aimed at improving participants' (i) mindfulness-based attention and interoception, (ii) socio-affective skills (compassion and prosocial motivation) and (iii) socio-cognitive skills (perspectivetaking) (Singer and Engert 2019).

The ReSource team employed a multitude of methods including brain-imaging techniques, computer-based behavioural performance tasks (game theoretical paradigms and hypothetical distribution tasks), psychometric self-report scales, app-based state assessments, and interviews. The researchers showed that social brain areas are plastic and that the areas targeted by the different training modules increased significantly in volume and cell density (Valk et al. 2017). These changes also correlated positively with improvements in behavioural performance tasks testing for presence, social affect and perspective-taking.

As part of the data analysis, researchers also examined the impact of the different practices on three different expressions of altruistic behaviours: altruistically motivated behaviours, norm motivated behaviours and self-reported pro-sociality (Böckler et al. 2018). Böckler et al. (2018) applied four game theoretical paradigms, two interactive computer tasks, two hypothetical distribution tasks and three self-report questionnaires as measures of pro-sociality. Only the affect-based care and compassion training effectively increased altruistically motivated behaviour. None of the training modules influenced norm-based behaviour, and all modules resulted in improvements in self-reported pro-sociality. The effect sizes of selfreported pro-sociality grew over the duration of the intervention, from small to medium to large, which might indicate progress with continued practice. Furthermore, increases in altruistically motivated PSB was negatively correlated with norm motivated PSB. The research by Böckler et al. (2018) shows that 'human pro-sociality is malleable and that distinct facets of pro-sociality can be systematically shaped by different types of mental trainings' (Böckler et al. 2018, p. 8).

Only two studies specifically explore the relationship between mindfulness and PEB while applying proper mediation analyses with pro-sociality variables (Panno et al. 2018; Loy and Reese 2019). Panno et al. (2018) studied the role of social dominance orientation as a mediator between mindfulness and PEB. Individuals with high social dominance orientation
Fig. 6 The three core practices taught and evaluated separately as part of the ReSource project (Singer and Engert 2019)

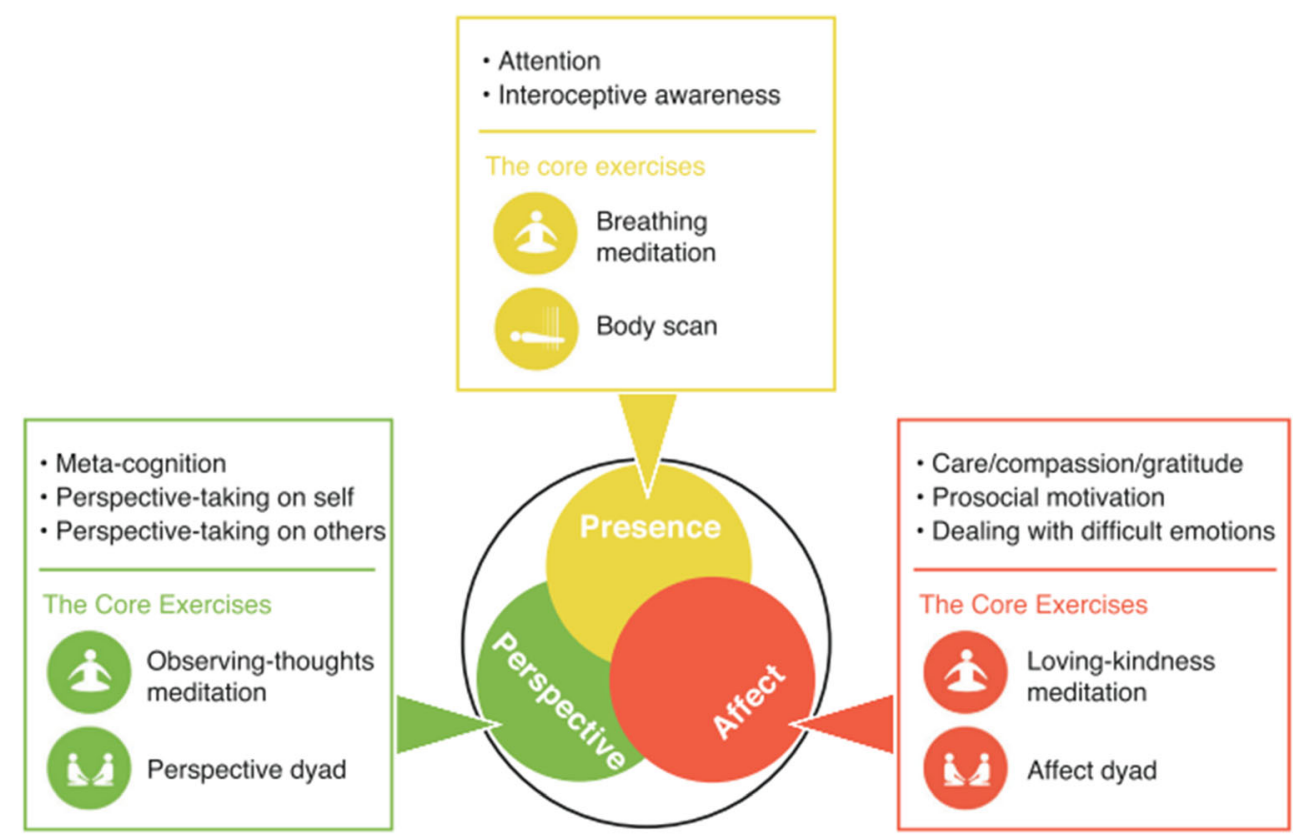

Current Opinion in Psychology 
understand that society should be organized in group-based hierarchies where the strong dominate over the weak and is associated with an anti-egalitarian worldview. In two studies, one survey with 300 students in Italy and one comparative study of a group of 44 Buddhist meditation practitioners and 53 non-practitioners, Panno et al. (2018) confirmed their hypothesis that the relationship between mindfulness and PEB is rooted in a more egalitarian view of the world. Meditators showed significantly less social dominance orientation than non-meditators, while performing better in PEB and their beliefs in global climate change. Moreover, social dominance orientation partly mediated the relationship between mindfulness and PEB. In another study, Loy and Reese (2019) also compared a group of 145 nonpractitioners with 113 'mind-body' practitioners, an umbrella term including both practitioners of meditation and movement practices such as yoga. They found that practitioners performed more PEB and were more supportive for climate policies, an effect that the authors found to be mediated by global self-definition but not by global self-investment. The authors interpreted this finding as evidence that mind-body practitioners might reflect more upon their interconnectedness, which was not necessarily connected with a call to act upon (Loy and Reese 2019). While this apparent lack of active engagement of mindfulness practitioners in changing societal conditions has increasingly been criticized by voices from inside and outside the mindfulness community (Walsh 2016; Purser 2019), mindfulness-based activism in form of nonviolent civil disobedience is on the rise ${ }^{1}$ (Dayley 2017; Dillard-Wrigth 2017; Abrahams 2019).

\section{Personal Values and Ethical Decision-Making}

Environmental psychologists agree that values are a fundamental predictor of environmental commitment. Individuals with strong transcendental values (altruistic and biospheric) and who are motivated by intrinsic values tend to show higher levels of engagement in PEB than those guided by extrinsic and materialistic values (Hedlund-de Witt et al. 2014; Steg 2016; de Groot and Thøgersen 2018; Gatersleben 2018). Furthermore, moral integrity also has been discussed as crucial to put those values into practice during situations of conflicting interests (Van der Werff et al. 2013). In the following, we present first research indicating a positive association between mindfulness and intrinsic and transcendental values.

In a multi-study research project combining three crosssectional as well as one quasi-experimental study, mindfulness was associated with decreased financial desire discrepancy, defined as the perceived gap between what one has and desires (Brown et al. 2009). Independent of economic status,

\footnotetext{
${ }^{1}$ Examples of organizations are https://www.nonviolent-conflict.org/ and https://rebellion.earth/
}

income and success in attaining financial goals, mindfulness was positively correlated with financial satisfaction and subjective well-being. The researchers further confirmed that a decline in financial desire discrepancy partially mediated the relationship between mindfulness and well-being. Brown et al. (2009) attributed this effect to the mindfulness teachings for greater appreciation of the present moment and the reorientation of life along intrinsic goals. Dhandra (2019) also confirmed a negative relationship between mindfulness and materialism, particularly reinforcing that green purchase intention, social conscious and frugal purchasing mediated the positive relationship between dispositional mindfulness and life satisfaction.

A cross-sectional study with a sample of over 500 mindfulness practitioners and non-practitioners provides further insight into the relationship between mindfulness practice and value-oriented living (Franquesa et al. 2017). They showed that there is a general positive association between meditation practice and values; however, only daily meditators demonstrated greater capacity for behaving in line with those values and scored higher on life fulfilment. Franquesa et al. (2017) also identified that decentering processes and the mindfulness facets describe and non-judge partially mediated the relationship between meditation practice and valued living. These are processes that could be reinforced not only by meditation but also by other practices and therapies (Franquesa et al. 2017).

In a qualitative study of more than 500 essays about consumers' understanding of 'mindful consumption', researchers examined if the engagement in mindfulness practices comes with a shift in consumer values and priorities (Milne et al. 2019). Milne et al. (2019) identified three segments of 'mindful' consumers: those with a (1) consumer first view, a (2) firm observer view and (3) an informed consumer view. While the first consumer segment included the smallest number of mindful practitioners, it stands for a mostly economic and qualityoriented perspective on mindful shopping. The other views, where mindfulness practitioners were more frequently represented, showed greater involvement with sustainability issues and the monitoring of company practices (Milne et al. 2019).

In line with the finding that mindfulness is associated with value-oriented living (Franquesa et al. 2017), three studies explicitly investigated associations between mindfulness and moral reasoning processes (Ruedy and Schweitzer 2010; Shapiro et al. 2012; Pandey et al. 2018). In a survey with 100 students in the USA, Ruedy and Schweitzer (2010) found a positive relationship between mindfulness and internal moral focus, as well as a more principled approach to ethical decision-making. Mindful participants also showed to be less willing to engage in unethical behaviour. However, a behavioural experiment showed that participants were found cheating in given tasks independent from their level of mindfulness (Ruedy and Schweitzer 2010). Yet the researchers 
found that more mindful participants cheated to a significantly lesser extent than less mindful ones (Ruedy and Schweitzer 2010). Shapiro et al. (2012) measured scores for moral reasoning and decision-making before, directly after, and 2 months after an 8-week mindfulness intervention, without comparing results to a control group. They established that the moral reasoning scores of participants did not change over the course of the training. Only at the 2 months follow-up measurement was there a significant increase in their moral decision-making score (Shapiro et al. 2012). A more recent study found that both dispositional mindfulness and mindfulness practice had positive effects on moral reasoning (Pandey et al. 2018). Pandey et al. (2018) identified that egocentric bias and compassion almost fully mediated this effect in complementary ways: mindfulness appeared negatively related to egocentrism, but positively associated with compassion. While these three studies provide preliminary evidence for a relationship between mindfulness, morality and ethical decision-making, researchers from the field of neurosciences began investigating if increased awareness of morally relevant internal and external stimuli could be responsible for mindfulness-induced improvements in moral decisionmaking (Sevinc and Lazar 2019).

\section{Openness to New Experiences}

The ability to open up to new ideas and the change of behaviours, as opposed to traditionalism and social conformity, is another important factor for the successful adoption of PEB (de Groot and Thøgersen 2018). This kind of openness, combined with a non-judgemental attitude, is one of the corner stones of mindfulness practice (Shapiro et al. 2006). Of those mindfulness scales dominating the research in mindfulness and PEB, only the Comprehensive Inventory of Mindfulness (CHIME) include a subscale for openness (Geiger et al. 2018; Medvedev et al. 2018). This might contribute to the fact that few studies have explicitly studied the link between mindfulness, openness and ecological mindsets.

One of such studies involved the survey with more than 500 hotel tourists (Barber and Deale 2014). Barber and Deale (2014) analysed if hotel guests with higher levels of dispositional mindfulness would be more willing to accept suggestions for sustainable practices in the diverse hotel locations. They found that more mindful guests were more receptive to innovative cues on PEB.

Newly emerging research in this area explores the effect of mindfulness on climate adaptation and disaster resilience (Wamsler 2018; Wamsler and Brink 2018). As part of a survey with 217 citizens at risk of severe climate conditions in Sweden, Wamsler and Brink (2018) studied the relation between dispositional mindfulness, the level and diversity of climate adaptation activity, climate beliefs, fatalistic behaviour and PEB. In an explorative study, they found that individuals with higher levels of mindfulness showed more openness to engage in climate adaptation actions and in measures that require community interaction, and they were more motivated by altruistic considerations. More mindful respondents also believed more in climate change, performed more PEB and appeared to be less fatalistic (Wamsler and Brink 2018).

This concludes the structured summary of empirical studies supporting the key theoretical links behind mindfulness and PEB. While the last section only sporadically touched on methodological weaknesses, a more comprehensive critique of the mindfulness and sustainability research is provided in the next section.

\section{Methodological Critique}

In the search for ways to initiate behaviour change in large parts of our society, it is tempting for those committed to sustainability to grasp at any straws that could offer relief to the crisis at hand. However, none of the above-mentioned studies confirms that the practice of mindfulness causes improvements in environmental awareness and PEB performance. Several methodological challenges must be overcome before we can start issuing political recommendations regarding the environmental benefits of widespread mindfulness practice.

Some publications already discuss a long list of methodological challenges inherent to the research of mindfulness (Grossman 2011; Creswell 2017; Goldberg et al. 2017; Goleman and Davidson 2017; Van Dam et al. 2018). The research on mindfulness and sustainability shares many of the quality concerns directed towards mindfulness research. This is only further exacerbated by the fact that the research combining both concepts is even more recent than the classical mindfulness research. The following section highlights some of the main issues specific to the research regarding mindfulness and sustainable behaviour change.

\section{Measuring Mindfulness: Trait (vs) Practice}

Mindfulness is considered a universal human capacity, a state of awareness accessible to everybody independent of culture and religion (Shapiro et al. 2018). In the academic literature, however, the term has been used to describe a variety of phenomena with little consensus about the technical definition or the mechanisms of mindfulness (Chiesa 2013). There are commonalities but also fundamental differences between 'cognitive mindfulness' as created by Ellen Langer and 'meditative mindfulness' based on Jon Kabat-Zinn (Hart et al. 2013). Kabat-Zinn defines mindfulness as the awareness that emerges through paying attention on purpose, in the present moment, and nonjudgmentally to the unfolding of experience 
moment by moment (Kabat-Zinn 2003). While most sustainability studies apply this definition, the operationalization of mindfulness varies and can be understood as either a temporary state achieved through meditation, an enduring/ dispositional trait, a recurrent/consistent meditation practice or an intervention (Vago and Silbersweig 2012).

These four aspects are interconnected: dispositional/trait mindfulness tends to be constant over time, but with repeated meditation practice it can be strengthened further (Brown et al. 2007; Kiken et al. 2015). The frequent stimulation of a mindful state through meditation increases mindfulness as a trait, due to changes in the neurobiological structures in the meditator's brain which lead to changes in neurocognitive processing (Hölzel et al. 2011; Vago and Silbersweig 2012; Kiken et al. 2015; Tang et al. 2017; Valk et al. 2017). Increases in trait mindfulness also have been identified as one of the underlying factors for long-lasting positive behavioural changes (Goleman and Davidson 2017). Mindfulness-based interventions aim to teach individuals the basic principles of meditation practice and therefore help initiate this process of selfdevelopment.

Most empirical studies studying mindfulness and PEB have relied on psychometric scales to measure dispositional mindfulness (see Table 1). A meta-analytical comparison of 12 cross-sectional studies revealed a small positive weighted overall-mean effect size of $r=0.199$ between diverse dispositional mindfulness measures and PEB (Geiger et al. 2019a). The focus on dispositional mindfulness has revealed that a thorough understanding of the inner dimensions of individuals is an important factor if we want to drive the social transformation towards sustainability (Wamsler and Brink 2018; Thiermann and Sheate 2020). However, the adequacy of and variability between those self-reported psychometric scales is widely criticized by mindfulness researchers (Grossman 2008; Chiesa 2013; Tang et al. 2015; Alsubaie et al. 2017; Creswell 2017; Goleman and Davidson 2017; Van Dam et al. 2018). Particularly the earlier studies in the field lack the necessary psychometric validation in their assessment of the dispositional mindfulness and the meditation experience of their populations. Even in those studies that do apply a validated mindfulness scale, the conceptual approaches are highly variable with some using a single dimension approach (focussing on the attention aspect of mindfulness) and others employing a multi-faceted construct in form of the Five Facets of Mindfulness Questionnaire (FFMQ). Many studies employing the FFMQ refrain from exploring the connection between the subscale level and the outcome parameters (Fischer et al. 2017), even though it would be informative to find out how each of the mindfulness facets contribute to sustainable attitudes and behaviours (Barbaro and Pickett 2016).

While many studies in the field do not assess mindfulness practice parameters, the conclusions often imply that it is the mindfulness practice that makes the difference. Several mindfulness and sustainability studies fail to include meditation practitioners in their sample and if they are included, they neglect to assess the frequency, type and level of mindfulness practice (Fischer et al. 2017). Due to these limitations, it remains questionable whether cross-sectional studies that exclusively build on dispositional mindfulness can provide justified conclusions regarding the relationship between the practice of mindfulness and performance in PEB. This is further exacerbated by the fact that the path for change depends largely on the type of meditation practiced by the individual (Singer and Engert 2019). For example, compassion meditation so far showed the greatest effect on pro-sociality and altruism (McCall et al. 2014; Hildebrandt et al. 2017; Valk et al. 2017; Böckler et al. 2018; Trautwein et al. 2020).

As shown in Table 1, only three cross-sectional studies have assessed the meditation practice of their respondents in relation to green behaviours (Jacob et al. 2009; Panno et al. 2018; Loy and Reese 2019). Loy and Reese (2019) assessed the existence of any mind-body practices (including yoga, tai chi and others) as a simple dichotomous variable (yes/no), while Panno et al. (2018) and Jacob et al. (2009) focussed on meditation and included measures of practice frequency. Jacob et al. (2009) performed the only study to also provide a measure for the level of progression in practice.

\section{Measuring PEB: Scales (vs) Environmental Impact}

Measurement is not only challenging regarding the construct of mindfulness. Environmental psychology typically observes several antecedent factors of PEB such as values, beliefs, attitudes, and worldviews. However, the proper quantification of PEB, defined as 'behaviour that harms the environment as little as possible, or even benefits the environment' (Steg and Vlek 2009, p. 309), and the determination of their associated environmental impact is not trivial (Gatersleben et al. 2002; Kormos and Gifford 2014; Gatersleben 2018; Lange and Dewitte 2019).

To successfully mitigate climate change, behavioural interventions need to focus on the behaviours with the highest potential environmental impact rather than those easiest to change (Clayton et al. 2016). Furthermore, researchers need to quantify the effectiveness of an intervention in terms of its mitigated environmental impact (Swim et al. 2011; Clayton et al. 2016). The routine approach to measure the effectiveness of behaviour change programs is the use of self-reported behaviour scales, which in their majority have not been validated and assess between one single item up to 66 items. Lange and Dewitte (2019) identified 42 such measures in 49 studies, but judged that only the General Ecological Behaviour measure (Kaiser and Wilson 2004) showed a sufficient level of psychometric validity. They also recommend a stronger focus on quantifiable impact criteria such as the ecological footprint or 
Table 1 Overview of studies on mindfulness and PEB, organized by study design features regarding mindfulness and PEB measures

\begin{tabular}{|c|c|c|c|c|c|}
\hline & Design & Antecedents of PEB & $\begin{array}{l}\text { Reported behaviour/PEB } \\
\text { scales }\end{array}$ & $\begin{array}{l}\text { Environmental } \\
\text { impact }\end{array}$ & $\begin{array}{l}\text { Researcher-observed } \\
\text { behaviour }\end{array}$ \\
\hline \multirow[t]{11}{*}{ Trait mindfulness } & $\mathrm{CS}$ & $\begin{array}{l}\text { Richter and Hunecke } \\
2020\end{array}$ & Richter and Hunecke 2020 & & \\
\hline & $\mathrm{CS}$ & Werner et al. 2020 & Werner et al. 2020 & & \\
\hline & $\mathrm{CS}$ & $\begin{array}{l}\text { Hunecke and Richter } \\
2019\end{array}$ & Hunecke and Richter 2019 & & \\
\hline & $\mathrm{CS}$ & Dhandra 2019 & Dhandra 2019 & & \\
\hline & $\mathrm{CS}$ & Geiger et al. 2018 & Geiger et al. 2018 & & \\
\hline & $\mathrm{CS}$ & Wamsler and Brink 2018 & Wamsler and Brink 2018 & & \\
\hline & $\mathrm{CS}$ & Barber and Deale 2014 & & & \\
\hline & $\mathrm{CS}$ & Howell et al. 2011 & & & \\
\hline & $\mathrm{CS}$ & & Amel et al. 2009 & & \\
\hline & $\mathrm{CS}$ & & Brown and Kasser 2005 & & \\
\hline & $\mathrm{CS}$ & $\begin{array}{l}\text { Brinkerhoff and Jacob } \\
1999\end{array}$ & & & \\
\hline \multirow[t]{4}{*}{ Mindfulness practice } & EX & Chan 2019 & Chan 2019 & & Chan 2019 \\
\hline & $\mathrm{IN}$ & Grabow et al. 2018 & & Grabow et al. 2018 & Grabow et al. 2018 \\
\hline & EX & Aspy and Proeve 2017 & & & \\
\hline & $\mathrm{CS}$ & Jacob et al. 2009 & Jacob et al. 2009 & & \\
\hline \multirow[t]{5}{*}{ Combination trait + practice } & $\mathrm{IN}$ & Böhme et al. 2018 & Böhme et al. 2018 & & \\
\hline & $\mathrm{IN}$ & Stanszus et al. 2019 & Stanszus et al. 2019 & & \\
\hline & $\mathrm{IN}$ & Geiger et al. 2019a & Geiger et al. 2019a & & \\
\hline & $\mathrm{CS}$ & Loy and Reese 2019 & Loy and Reese 2019 & & \\
\hline & $\mathrm{CS}$ & Panno et al. 2018 & Panno et al. 2018 & & \\
\hline $\begin{array}{l}\text { Theoretical/review/qualitative/ } \\
\text { programmes }\end{array}$ & \multicolumn{5}{|c|}{$\begin{array}{l}\text { Bernal et al. 2018; Thiermann and Sheate 2020; Frank et al. 2019a, b; Geiger et al. 2019b; Milne et al. 2019; Wamsler } \\
\text { 2019; Ives et al. 2019; Livingstone 2019; Patel and Holm 2018; Schutte and Malouff 2018; Wamsler 2018; Fischer } \\
\text { et al. 2017; Stanszus et al. 2017; Wamsler et al. 2017; Wamsler 2018; Wamsler 2020; Bahl et al. 2016; Barrett et al. } \\
\text { 2016; Fung et al. 2016; Siqueira and Pitassi 2016; Ericson et al. 2014; Armstrong } 2012\end{array}$} \\
\hline
\end{tabular}

$C S$ cross-sectional, $E X$ experimental manipulation, $I N$ intervention (pre/post comparison)

greenhouse gas emissions. Generally, behavioural studies do not combine psychometric scales with quantitative measures of the same behaviour (Kormos and Gifford 2014). The assessment of observable behaviour via experimental manipulation such as the pro-environmental behaviour task (PEBT) is even more rare (Lange et al. 2018; Lange and Dewitte 2019).

To explore the relationship between mindfulness and PEB, Fischer et al. (2017) recommend that researchers clearly define if they are assessing the intention to behave sustainably or the actual impact of such behaviours. They also suggest that mindfulness research should focus on high impact behaviours such as meat consumption, transport and housing habits. Barbaro and Pickett (2016) expressed the need for more reliable measures than self-report questionnaires and suggest that future studies could assess behaviours using diaries or in behavioural tasks in laboratory settings. Table 1 highlights the lack of mindfulness and sustainability studies that assess the environmental impact of behaviours and illustrates the dominance of antecedent factors and self-reported behaviour scales. The only programme designed to evaluate behavioural impact via environmental impact indicators such as greenhouse gas emissions from diet, transportation and household energy is the Mindful Climate Action programme (Grabow et al. 2018). However, results are limited to a pilot and feasibility study.

\section{Rigour of Quantitative Studies}

A major challenge for the mindfulness and sustainability field is the low quality of sampling techniques (Fischer et al. 2017). Most studies are based on convenience samples and biased populations, which carries the risk of floor and ceiling effects when psychometric scales are very specific to those populations. Especially, the lack of individuals with formal meditation experience in samples is an issue, exacerbated by the fact that meditation practitioners tend to interpret the mindfulness scales differently from non-practitioners. It is therefore indispensable that future studies involve general population samples and explicitly investigate samples with meditation novices and experts (Fischer et al. 2017). Another factor needing further investigation is the influence of cultural differences on study measures as mentioned by Wamsler et al. (2017). 
Regarding the study design and methodology of studies in the field of mindfulness and sustainability, there is a clear dominance of correlational studies with measurements at only one time point (Ericson et al. 2014). The authors also identified that correlational studies need to branch out to a greater variety of potential mediating variables, such as compassion, responsibility, personal norms, and health orientation. Furthermore, Fischer et al. (2017) suggest that moderating factors should also be analysed, such as the hypothesis that mindfulness helps to close the attitude-behaviour gap commonly found in PEB literature (Kollmuss and Agyeman 2002; Ertz et al. 2016). In general, Fischer et al. (2017) lament that many authors in the field fail to record non-significant effects.

While correlational studies dominate the field and provide initial evidence that mindfulness is associated with improved consumption behaviour, intervention studies are scarce and methodologically weak (Fischer et al. 2017). Some of the limitations are small samples (e.g. $n=6$ in Armstrong 2012) and a lack of control groups and randomization. To make a valid claim that mindfulness causes improvements in PEB, future studies must improve in quality, provide experimental evidence and include longitudinal study designs (Ericson et al. 2014; Barbaro and Pickett 2016; Siqueira and Pitassi 2016; Geiger et al. 2019b). Behavioural changes from mindfulness might take a long time, dependent on the individual's starting point and the intensity of engagement in practice. Therefore, future studies should explore the long-term effects of mindfulness practice in areas such as lifestyles, political orientation and PEB. This includes the monitoring of meditation practice patterns, in terms of their frequency, the techniques applied and the level of exposure to mindfulness teachings.

\section{First Explorations of Causality}

Two research teams have tried to approach the issue of causality between mindfulness and PEB. Both have developed their own mindfulness programs which blend mindfulnessrelated content and practices, as well as health and sustainability-related modules in the classical format of an 8week-long programme with weekly sessions and homework (Barrett et al. 2016; Stanszus et al. 2017).

In the USA, the Mindful Climate Action Program makes an attempt to quantify changes in the environmental impact associated with key behaviours such as home energy use, car use, active transport, dietary change and purchasing (Barrett et al. 2016). Over time, the researchers assess the evolution of climate and energy knowledge in the form of a test. They not only assess the diet-related carbon footprint three times by recall in a self-administered 24-h dietary assessment tool but also apply food frequency questionnaires, dietary records and diet history interviews. A smart phone application and odometer readings of participants' personal car provide information on the emissions related to transportation, and individuals report their monthly energy usage in kilowatt per hour and total natural gas consumption in therms per month. Psychometric scales only serve the assessment of mindfulness, well-being and health. In a pilot study with 16 participants, the researchers confirmed the feasibility of the programme procedures. The next step is to roll it out in a larger intervention (Grabow et al. 2018).

The sustainable consumption specific programme developed in Germany was applied in an intervention with university students (Stanszus et al. 2019), one with adolescents at a school (Böhme et al. 2018) and one with a mixed sample of 131 students and company employees (Geiger et al. 2019a). Stanszus et al. (2019) confirmed that in a sample of 72 students, the experimental group developed more mindful eating patterns in comparison to the waitlist-control group. Only the follow-up interviews with selected individuals showed a subtle tendency of stronger sustainability-related attitudes or intentions (pre-behavioural). In the study with 85 adolescents, Böhme et al. (2018) found a small quantitative improvement in the sustainable food behaviour of the experimental group, but not for clothing. In some cases, follow-up interviews revealed changes in level of awareness of environmental behaviours. Geiger et al. (2019a) found that the intervention caused increases in dispositional mindfulness but not in consumption behaviours and attitudes (Geiger et al. 2019a). They only detected changes in variables that are known to be indirectly related to PEB: an increased sense of well-being and decreased material values.

In reflection of these intervention studies and the small overall weighted effect size of the association between dispositional mindfulness and PEB, researchers expressed scepticism regarding the causal influence of mindfulness on PEB (Geiger et al. 2019b). However, they also encourage further research because the changes in indirectly related predictor variables, such as subjective well-being and reduced materialism might indicate a slower transition process to more PEB than the classical 8-week period with a couple of months of follow-up. Therefore, Geiger et al. (2019b) suggest to increase the duration of interventions as well as the evaluation timeframe and to provide continuing meditation practice support. They also suggest to experiment with varying types of interventions, such as one that involves nature experiences.

A problem of hybrid models, including those built by the researchers in Germany and the USA, is the difficulty to determine whether any changes in attitudes and behaviour can be attributed solely to the meditation practice. If researchers manipulate more than one independent variable (e.g. meditation practice, health-related knowledge, environmental knowledge, nature exposure), it becomes challenging to isolate the effect of any of these on the responding variable (PEB) (Kantowitz et al. 2015). At time of writing this article, no peerreviewed academic article assessed the effect of a classical 8- 
week programme, such as the mindfulness-based stress reduction (MBSR) programme, on PEB. There also is a lack of studies evaluating the long-term lifestyle changes of mindfulness practitioners as they progress in their practice.

\section{Qualitative and Mixed Methods}

Several authors advocate for a stronger integration of qualitative methods in the research of mindfulness and sustainability (Grossman 2008; Ericson et al. 2014; Fischer et al. 2017; Böhme et al. 2018). Qualitative methods, and particularly in-depth interviews, are a valuable resource to gain a nuanced understanding of the connection between mindfulness and PEB which helps the development of new theories and hypotheses (Levitt et al. 2018). The advantage of qualitative methods is their potential to explore the differences in the experiences, reasoning, feelings, and motivations of mindfulness practitioners and non-practitioners, which might reveal new investigative branches that so far have fallen through the net of quantitative research. To date, only a small fraction of studies in the field apply qualitative methods, mostly constituting only one part in larger mixed methods studies (Armstrong 2012; Von Essen and Mårtensson 2014; Böhme et al. 2018; Frank et al. 2019b; Geiger et al. 2019a; Stanszus et al. 2019). The lack of qualitative studies exploring the questions why and how mindfulness might impact environmental awareness and PEB is surprising for such a recently emerging area of research. Fischer et al. (2017) and Ericson et al. (2014) recommend both qualitative and mixed methods studies to improve the depth of knowledge in mindfulness and sustainability, particularly if they are based on precise research questions and clearly discuss sampling and data collection procedures. In case of mixed methods studies, they need to be based on a careful triangulation of the quantitative and qualitative data (Fischer et al. 2017; Creswell and Plano Clark 2018). In all cases, the reporting of the qualitative and mixed methods research process should follow standard procedures of qualitative research (Levitt et al. 2018).

\section{The Way Forward: a Research Agenda}

The insights from this review are encouraging: In only 20 years and with a minimum of resources, a solid amount of theoretical and empirical work have offered first glances into the relationship between mindfulness, PEB and the transition towards a more sustainable society. These pioneer studies lay important groundwork for the next decades of research in the field and provide valuable arguments for investments in larger and methodologically more rigorous studies.
In Table 2, we propose a research agenda to spark discussions about future research pathways in mindfulness and sustainability. We understand that the long-term goal of researchers in the area should be to, first, establish whether mindfulness causes behaviours and society to become more sustainable and, second, to provide structural recommendations for mindfulness policies and educational programs that generate the greatest benefit to our society in terms of both well-being and sustainability. Thereby, it is crucial to mention that the study of causality is not limited to purely quantitative methods. Inspired by principles from the UK Government's Magenta Book for policy evaluation (HM Treasury 2020a), our research agenda works towards a logic model and the development of a theory of change that 'considers the causal mechanisms by which an intervention is expected to achieve its outcomes, basing this theory on the gathering and synthesis of evidence' (HM Treasury 2020a, p. 25). A theory of change helps to estimate the resources and activities needed to deliver an intervention (output), the early or medium-term results (outcomes) and the long-term results (impact). The policy evaluation literature also increasingly recognizes the challenges posed by complexity, especially in the environmental field (HM Treasury 2020b). Details setting out the research agenda for mindfulness and sustainability can be observed in Table 2; however, we want to highlight three main priorities for this research agenda.

\section{People and Practice—Inputs}

Because dispositional mindfulness can only be manipulated indirectly via mindfulness practices, we suggest that it should be analysed as one of the many mediating, moderating and interacting variables defining the process of change. By placing people and the practice of mindfulness as the input variables in our logic model, we emphasize the need to better understand how different interventions and practices affect individuals, while also considering their personal characteristics and predispositions. Equally, there is room to branch out and study a variety of policy intervention options that can promote such changes of the inner dimensions of individuals, alternative to meditation.

\section{Significant Behaviours-Outcomes}

Regarding the outcomes, we need to focus on the behaviours that matter most. If we can show that mindfulness causes significant lifestyle changes and we successfully quantify the environmental improvements over the short- and mediumterm, only then can we then draw conclusions regarding the efficacy of mindfulness programs to render individuals more sustainable. 
Table 2 Mindfulness and sustainability research agenda

\begin{tabular}{|c|c|c|c|c|c|c|}
\hline \multicolumn{7}{|c|}{ Research Agenda: Mindfulness \& Sustainability } \\
\hline & \multicolumn{2}{|c|}{ INPUT } & \multirow{2}{*}{ Process } & OUTCOME & \multirow{2}{*}{ Process } & IMPACT \\
\hline & People & Practice & & Individual & & Society \\
\hline $\begin{array}{l}\text { VARIABLES: } \\
\text { What to } \\
\text { study? }\end{array}$ & 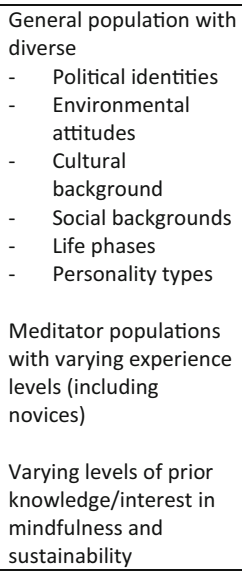 & $\begin{array}{ll}- & \begin{array}{l}\text { Type of intervention } \\
\text { (only mindfulness, }\end{array} \\
\text { blended programs) } \\
- & \text { Type of practice } \\
- & \text { Frequency } \\
- & \text { Experience level } \\
- & \text { Duration/ intensity } \\
- & \text { Maintenance level } \\
\text { (post-intervention) } \\
-\quad & \text { Guided/un-guided } \\
- & \text { Alone/group settings } \\
- & \text { Readings/teachings } \\
- & \text { Alternatives } \\
& \text { interventions to } \\
& \text { meditation }\end{array}$ & 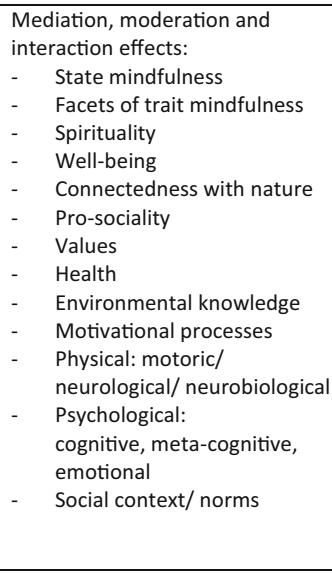 & $\begin{array}{ll}- & \text { PEB Scales } \\
- & \text { High impact } \\
& \text { behaviours } \\
- & \text { Quantify } \\
\text { environmental } & \text { impact } \\
\text { - } & \text { Observed } \\
\text { behaviours } \\
\text { - } & \text { Spill-over } \\
\text { - } & \text { patterns } \\
\text { Lifestyles }\end{array}$ & $\begin{array}{l}\text { Mediation, } \\
\text { moderation and } \\
\text { interaction effects: } \\
\text { - } \quad \text { Social } \\
\text { interaction/ } \\
\text { norms } \\
\text { - } \quad \text { Political } \\
\text { engagement } \\
\text { - } \quad \text { Social activism } \\
\text { - } \quad \text { Organisational } \\
\text { change } \\
\text { - Education } \\
\text { - Consumption } \\
\text { patterns }\end{array}$ & $\begin{array}{l}\text { Projections and } \\
\text { measurement of } \\
\text { social changes: } \\
\text { - Social } \\
\text { processes/ } \\
\text { democracy } \\
\text { - Environmental } \\
\text { impact } \\
\text { - Sub-cultures and } \\
\text { political } \\
\text { identities }\end{array}$ \\
\hline $\begin{array}{l}\text { AREAS: } \\
\text { Who } \\
\text { studies? }\end{array}$ & Psychology, Sociology & $\begin{array}{l}\text { Contemplative science, } \\
\text { Education }\end{array}$ & $\begin{array}{l}\text { Psychology, Contemplative } \\
\text { science, Education, Neuroscience, } \\
\text { Public health, Sociology, } \\
\text { Philosophy }\end{array}$ & $\begin{array}{l}\text { Psychology, } \\
\text { Environmental science }\end{array}$ & $\begin{array}{l}\text { Social psychology, } \\
\text { Sociology, Political } \\
\text { science, } \\
\text { Management, } \\
\text { Philosophy }\end{array}$ & $\begin{array}{l}\text { Sociology, } \\
\text { Environmental } \\
\text { science, Political } \\
\text { science, Economics, } \\
\text { Philosophy }\end{array}$ \\
\hline \multirow{3}{*}{$\begin{array}{l}\text { METHODS: } \\
\text { How to } \\
\text { study? }\end{array}$} & \multicolumn{6}{|c|}{ Type of research: cross-sectional (correlations and comparisons), experiments, interventions (short and long-term), longitudinal studies } \\
\hline & \multicolumn{6}{|c|}{ Quantitative assessment: frequency diaries, self-report scales, objective measures (bills, applications), observation } \\
\hline & \multicolumn{6}{|c|}{$\begin{array}{l}\text { Qualitative assessment: interviews, focus groups, (participatory) observation, case studies, action research, content analysis, new methods (systems thingking, } \\
\text { creative research, digital platforms, quantum social theory) }\end{array}$} \\
\hline
\end{tabular}

\section{Processes-Impacts}

Based on correlational research, we have acquired some understanding of the processes that might be involved in individual behaviour change. However, statements regarding the societal impact of mindfulness are mostly theoretical and abstract. If we want to promote mindfulness on a political level for the sake of sustainability, we need to understand the processes involved in taking the suggested benefits from the individual level into society (the theories of change in evaluation terms).

Evaluating long-term impact in policy interventions is notoriously difficult because few studies last long enough to evaluate beyond short-term outcomes. Long-term impact, especially in the environmental field, may take many years to materialize (Sheate et al. 2016; HM Treasury 2020b). But more informed theories of change that seek to explain the pathways that link outcomes to impacts would enable mindfulness-based interventions for sustainability to be evaluated for their effectiveness in delivering outcomes.

Qualitative studies, surprisingly lacking to date in this field, can help provide deeply rich explanations as to why and how people respond to interventions, as recognized in wider complexity evaluation (Sheate et al. 2016; HM Treasury 2020b). In so doing, they can also provide a means to evaluate the counterfactual at the same time as the intervention-by asking people to compare how they would have responded previously. Qualitative studies are not, of course, without their own limitations, but those are no greater than many of the quantitative and mixed methods studies already critiqued in this article. The development of new methods in the social sciences is continuous, following the need to study contemporary challenges in all their complexity and interdependence. Examples for such developments include systems thinking methods, integral theory, new digital platforms such as the SenseMaker® software, ${ }^{2}$ creative research methods and methods based on quantum social theory (O'Brien 2016).

It will be challenging to find and organize the various factors and processes by which mindfulness and sustainability interact, as both concepts each involve a great deal of complexity and controversy by themselves. To produce high-quality studies, addressing the three priority areas above, it will need the fruitful collaboration between experts of a variety of scientific fields such as contemplative studies, psychology, neuroscience, sustainability science, environmental science, economics and social science. Such a diversity of expertise necessarily comes accompanied by a rich repertoire in experimental, quantitative and qualitative research methods and perspectives.

\footnotetext{
${ }^{2}$ https://cognitive-edge.com/sensemaker/
} 


\section{Conclusion}

The greatest challenge identified in this review is the need to shift the mindfulness and sustainability research narrative and embark in a collaborative and creative effort to study the causality between mindfulness and sustainability. While future research should build on the wealth of existing theoretical and correlational research, we need to go beyond and also question the epistemological and ontological assumptions we are bringing to the task. A future narrative should uncover and disentangle the multi-faceted processes that transform the inner dimensions of individuals. This entails a detailed study of the triggers for change (e.g. different mindfulness practices) and the outcome of the change (e.g. behaviours and impact). While we already have a thorough inventory of ideas for individual change processes, we need to ramp up our efforts to understand how sustainability spreads from the individual level into local, regional and global communities.

With this in mind, it might need a rethinking of how to explore causality between mindfulness and sustainability. Researchers will have to invest in more long-term studies and go beyond what we already know from the classical, health-related mindfulness research. The typical 8-week mindfulness course with pre-/post-evaluation might not be the most appropriate way to study the change of sustainability factors which seem to need more time to grow. Rejecting causality because of a lack of change in self-report measures after an 8-week course is as premature as declaring causality without understanding the full picture of an individual's environment, personality, prior socialization and interests as well as their commitment and experience in practicing formal and informal mindfulness. In this regard, much can be learned from the experience of wider complexity evaluation. To seriously progress our understanding of the connection between mindfulness and sustainability, it is time to find alternative methods, including qualitative work and new methods of knowledge generation. Overall, this is good news: the mindfulness and sustainability research is ready to grow out of its infancy stage. There is room for innovation and creativity that could benefit both the research in mindfulness and sustainability as separate fields, as well as in their combination. Exciting times have begun to form new interdisciplinary alliances and walk the steps towards becoming an established scientific field of inquiry.

Acknowledgments The authors thank the UK Economic and Social Research Council Doctoral Training Partnership (ESRC-DTP, Award Number 1917483) and the Imperial College Centre for Environmental Policy for the scholarship provided to the first author.

\section{Compliance with Ethical Standards}

Conflict of Interest The authors declare that they have no competing interest.
Open Access This article is licensed under a Creative Commons Attribution 4.0 International License, which permits use, sharing, adaptation, distribution and reproduction in any medium or format, as long as you give appropriate credit to the original author(s) and the source, provide a link to the Creative Commons licence, and indicate if changes were made. The images or other third party material in this article are included in the article's Creative Commons licence, unless indicated otherwise in a credit line to the material. If material is not included in the article's Creative Commons licence and your intended use is not permitted by statutory regulation or exceeds the permitted use, you will need to obtain permission directly from the copyright holder. To view a copy of this licence, visit http://creativecommons.org/licenses/by/4.0/.

\section{References}

Abrahams, M. (2019). The Buddhists of Extinction Rebellion. Tricycle the Buddhist Review. Retrieved from https:/tricycle.org/trikedaily/ extinction-rebellion-buddhists/. Accessed 20 Dec 2019.

Alsubaie, M., Abbott, R., Dunn, B., Dickens, C., Keil, T. F., Henley, W., \& Kuyken, W. (2017). Mechanisms of action in mindfulness-based cognitive therapy (MBCT) and mindfulness-based stress reduction (MBSR) in people with physical and/or psychological conditions: A systematic review. Clinical Psychology Review, 55(August 2016), 74-91. https://doi.org/10.1016/j.cpr.2017.04.008.

Amel, E. L., Manning, C. M., \& Scott, B. a. (2009). Mindfulness and Sustainable Behavior: Pondering Attention and Awareness as Means for Increasing Green Behavior. Ecopsychology, 1(1), 14 25. https://doi.org/10.1089/eco.2008.0005.

Armstrong, A. (2012). Mindfulness and consumerism: a social psychological investigation. ProQuest.

Aspy, D. J., \& Proeve, M. (2017). Mindfulness and Loving-Kindness Meditation: Effects on Connectedness to Humanity and to the Natural World. Psychological Reports, 120(1), 102-117. https:// doi.org/10.1177/0033294116685867.

Baer, R. A., Smith, G. T., Hopkins, J., Krietemeyer, J., \& Toney, L. (2006). Using self-report assessment methods to explore facets of mindfulness. Assessment, 13(1), 27-45. https://doi.org/10.1177/ 1073191105283504

Bahl, S., Milne, G. R., Ross, S. M., Mick, D. G., Grier, S. A., Chugani, S. K., et al. (2016). Mindfulness: Its transformative potential for consumer, societal, and environmental weil-being. Journal of Public Policy and Marketing, 35(2), 198-210. https://doi.org/10.1509/ jppm.15.139.

Bain, P. G., Milfont, T. L., Kashima, Y., Bilewicz, M., Doron, G., Garoarsdóttir, R. B., et al. (2016). Co-benefits of addressing climate change can motivate action around the world. Nature Climate Change, 6(2), 154-157. https://doi.org/10.1038/nclimate2814.

Barbaro, N., \& Pickett, S. M. (2016). Mindfully green: Examining the effect of connectedness to nature on the relationship between mindfulness and engagement in pro-environmental behavior. Personality and Individual Differences, 93, 137-142. https://doi.org/10.1016/j. paid.2015.05.026.

Barber, N. A., \& Deale, C. (2014). Tapping Mindfulness to Shape Hotel Guests' Sustainable Behavior. Cornell Hospitality Quarterly, 55(1), 100-114. https://doi.org/10.1177/1938965513496315.

Barrett, B., Grabow, M., Middlecamp, C., Mooney, M., Checovich, M. M., Converse, A. K., et al. (2016). Mindful climate action: Health and environmental co-benefits from mindfulness-based behavioral training. Sustainability (Switzerland), 8(10), 1-20. https://doi.org/ 10.3390/su8101040.

Beckage, B., Gross, L. J., Lacasse, K., Carr, E., Metcalf, S. S., Winter, J. M., et al. (2018). Linking models of human behaviour and climate 
alters projected climate change. Nature Climate Change, 8(1), 7984. https://doi.org/10.1038/s41558-017-0031-7.

Becke, G. (Ed.). (2014). Mindful Change in Times of Permanent Reorganization. https://doi.org/10.1007/978-3-642-38694-7

Bernal, E., Edgar, D., \& Burnes, B. (2018). Building Sustainability on Deep Values Through Mindfulness Nurturing is. Ecological Economics, 146, 645-657. https://doi.org/10.1016/j.ecolecon. 2017.12.003.

Böckler, A., Tusche, A., Schmidt, P., \& Singer, T. (2018). Distinct mental trainings differentially affect altruistically motivated, norm motivated, and self-reported prosocial behaviour. Scientific Reports, 8(1), 1-14. https://doi.org/10.1038/s41598-018-31813-8.

Böhme, T., Stanszus, L. S., Geiger, S. M., Fischer, D., \& Schrader, U. (2018). Mindfulness training at school: Away to engage adolescents with sustainable consumption? Sustainability (Switzerland), 10(10), 1-22. https://doi.org/10.3390/su10103557.

Brinkerhoff, M. B., \& Jacob, J. (1999). Mindfulness and quasi-religious meaning systems: An empirical exploration within the context of ecological sustainability and deep ecology. Journal for the Scientific Study of Religion, 38(4), 524-542. https://doi.org/10. 2307/1387610.

Bristow, J. (2018). Mindfulness in politics and public policy. Current Opinion in Psychology, 28, 87-91. https://doi.org/10.1016/j. copsyc.2018.11.003.

Brown, K. W., \& Kasser, T. (2005). Are psychological and ecological well-being compatible? The role of values, mindfulness, and lifestyle. Social Indicators Research, 74(2), 349-368. https://doi.org/ 10.1007/s11205-004-8207-8.

Brown, K. W., \& Ryan, R. M. (2003). The Benefits of Being Present: Mindfulness and Its Role in Psychological Well-Being. Journal of Personality and Social Psychology, 84(4), 822-848. https://doi.org/ 10.1037/0022-3514.84.4.822.

Brown, K. W., Ryan, R. M., \& Creswell, J. D. (2007). Mindfulness: Theoretical Foundations and Evidence for its Salutary Effects. Psychological Inquiry, 18(4), 211-237. https://doi.org/10.1080/ 10478400701598298.

Brown, K. W., Kasser, T., Ryan, R. M., Alex Linley, P., \& Orzech, K. (2009). When what one has is enough: Mindfulness, financial desire discrepancy, and subjective well-being. Journal of Research in Personality, 43(5), 727-736. https://doi.org/10.1016/j.jrp.2009.07. 002.

Carmody, J., \& Baer, R. A. (2008). Relationships between mindfulness practice and levels of mindfulness, medical and psychological symptoms and well-being in a mindfulness-based stress reduction program. Journal of Behavioral Medicine, 31(1), 23-33. https://doi. org/10.1007/s10865-007-9130-7.

Chambers, R., Gullone, E., \& Allen, N. B. (2009). Mindful emotion regulation: An integrative review. Clinical Psychology Review, 29(6), 560-572. https://doi.org/10.1016/j.cpr.2009.06.005.

Chan, E. Y. (2019). Mindfulness promotes sustainable tourism: the case of Uluru. Current Issues in Tourism, 22(13), 1526-1530. https://doi. org/10.1080/13683500.2018.1455647.

Chiesa, A. (2013). The Difficulty of Defining Mindfulness: Current Thought and Critical Issues. Mindfulness, 4(3), 255-268. https:// doi.org/10.1007/s12671-012-0123-4.

Ciarrochi, J., \& Godsell, C. (2013). Mindfulness-based emotional intelligence: Research and training. In Linking Emotional Intelligence and Performance at Work: Current Research Evidence with Individuals and Groups. https://doi.org/10.4324/9780203763896

Clayton, S., Devine-Wright, P., Stern, P. C., Whitmarsh, L., Carrico, A., Steg, L., et al. (2015). Psychological research and global climate change. Nature Climate Change, 5(7), 640-646. https://doi.org/10. 1038/nclimate2622.

Clayton, S., Devine-Wright, P., Swim, J., Bonnes, M., Steg, L., Whitmarsh, L., \& Carrico, A. (2016). Expanding the role for psychology in addressing environmental challenges. American Psychologist, 71(3), 199-215. https://doi.org/10.1037/a0039482.

Corral Verdugo, V. (2012). The positive psychology of sustainability. Environment, Development and Sustainability, 14(5), 651-666. https://doi.org/10.1007/s10668-012-9346-8.

Corral-Verdugo, V., Mireles-Acosta, J., Tapia-Fonllem, C., \& FraijoSing, B. (2011). Happiness as correlate of sustainable behavior: A study of pro-ecological, frugal, equitable and altruistic actions that promote subjective wellbeing. Human Ecology Review, 18(2), 95104. https://doi.org/10.3390/su5020711.

Costello, A., Abbas, M., Allen, A., Ball, S., Bell, S., Bellamy, R., et al. (2009). Managing the health effects of climate change. Lancet and University College London Institute for Global Health Commission. The Lancet, 373(9676), 1693-1733. https://doi.org/10.1016/S01406736(09)60935-1.

Creswell, J. D. (2017). Mindfulness Interventions. Annual Review of Psychology, 68(1), 491-516. https://doi.org/10.1146/annurevpsych-042716-051139.

Creswell, J. W., \& Plano Clark, V. L. (2018). Designing and conducting mixed methods research. Retrieved from https://imp-primo.hosted. exlibrisgroup.com/primo-explore/fulldisplay?docid=44IMP ALMA_DS2193273900001591\&context $=\mathrm{L} \& \mathrm{vid}=\mathrm{ICL}^{-}$ VU1\&lang=en_US\&search_scope $=$ LRSCOP_44IMP\&adaptor= LocalSearchEngine \& is Frbr $=$ true $\&$ ta $b=a 11 \&$ query $=$ any,contains,DesigningandConducting

Dayley, G. (2017). Mindful Activism: The Power of Mindfulness in the Streets. Retrieved June 2, 2020, from International Center on Nonviolent Conflict website: https://www.nonviolent-conflict.org/ blog_post/mindful-activism-power-mindfulness-streets/

de Groot, J. I. M., \& Thøgersen, J. (2018). Values and Pro-Environmental Behaviour. In L. Steg, A. van de Berg, \& J. I. M. de Groot (Eds.), Environmental Psychology (pp. 167-178). https://doi.org/10.1002/ 9781119241072.ch17.

Dhandra, T. K. (2019). Achieving triple dividend through mindfulness: More sustainable consumption, less unsustainable consumption and more life satisfaction. Ecological Economics, 161(March), 83-90. https://doi.org/10.1016/j.ecolecon.2019.03.021.

Dillard-Wrigth, D. B. (2017). Mindfulness and Activism. Retrieved June 2, 2020, from Psychology Today website: https://www. psychologytoday.com/us/blog/boundless/201702/mindfulness-andactivism

Djernis, L., Poulsen, S., Dahlgaard, \& O’Toole. (2019). A Systematic Review and Meta-Analysis of Nature-Based Mindfulness: Effects of Moving Mindfulness Training into an Outdoor Natural Setting. International Journal of Environmental Research and Public Health, 16(17), 3202. https://doi.org/10.3390/ijerph16173202.

Donald, J. N., Sahdra, B. K., Van Zanden, B., Duineveld, J. J., Atkins, P. W. B., Marshall, S. L., \& Ciarrochi, J. (2018). Does your mindfulness benefit others? A systematic review and meta-analysis of the link between mindfulness and prosocial behaviour. British Journal of Psychology. https://doi.org/10.1111/bjop.12338

Ericson, T., Kjnstad, B. G., \& Barstad, A. (2014). Mindfulness and sustainability. Ecological Economics, 104, 73-79. https://doi.org/10. 1016/j.ecolecon.2014.04.007.

Ertz, M., Karakas, F., \& Sarigöllü, E. (2016). Exploring pro-environmental behaviors of consumers: An analysis of contextual factors, attitude, and behaviors. Journal of Business Research, 69(10), 39713980. https://doi.org/10.1016/j.jbusres.2016.06.010.

Ferguson, M. L. (2016). Symposium: Mindfulness and Politics. New Political Science, 38(2), 201-205. https://doi.org/10.1080/ 07393148.2016.1153190.

Fischer, D., Stanszus, L. S., Geiger, S., Grossman, P., \& Schrader, U. (2017). Mindfulness and sustainable consumption: A systematic literature review of research approaches and findings. Journal of Cleaner Production, 162, 544-558. https://doi.org/10.1016/j. jclepro.2017.06.007. 
Frank, P., Fischer, D., \& Wamsler, C. (2019a). Mindfulness, Education, and the Sustainable Development Goals. In Achieving the Sustainable Development Goals: Global Governance Challenges (pp. 1-11). https://doi.org/10.1007/978-3-319-69902-8_105-1.

Frank, P., Sundermann, A., \& Fischer, D. (2019b). How mindfulness training cultivates introspection and competence development for sustainable consumption. International Journal of Sustainability in Higher Education, 20(6), 1002-1021. https://doi.org/10.1108/ IJSHE-12-2018-0239.

Franquesa, A., Cebolla, A., García-Campayo, J., Demarzo, M., Elices, M., Pascual, J. C., \& Soler, J. (2017). Meditation Practice Is Associated with a Values-Oriented Life: the Mediating Role of Decentering and Mindfulness. Mindfulness, 8(5), 1259-1268. https://doi.org/10.1007/s12671-017-0702-5.

Fung, T. T., Long, M. W., Hung, P., \& Cheung, L. W. Y. (2016). An Expanded Model for Mindful Eating for Health Promotion and Sustainability: Issues and Challenges for Dietetics Practice. Journal of the Academy of Nutrition and Dietetics, 116(7), 10811086. https://doi.org/10.1016/j.jand.2016.03.013.

Garland, E. L., Farb, N. A., Goldin, R., P, \& Fredrickson, B. L. (2015). Mindfulness Broadens Awareness and Builds Eudaimonic Meaning: A Process Model of Mindful Positive Emotion Regulation. Psychological Inquiry, 26(4), 293-314. https://doi.org/ 10.1080/1047840X.2015.1064294.

Gatersleben, B. (2018). Measuring Environmental Behaviour. In L. Steg, A. van de Berg, \& J. I. M. de Groot (Eds.), Environmental Psychology (pp. 155-166). https://doi.org/10.1002/ 9781119241072.ch16.

Gatersleben, B., Steg, L., \& Vlek, C. (2002). Measurement and determinants of environmentally significant consumer behavior. Environment and Behavior, 34(3), 335-362. https://doi.org/10. 1177/0013916502034003004.

Geiger, S. M., Otto, S., \& Schrader, U. (2018). Mindfully green and healthy: An indirect path from mindfulness to ecological behavior. Frontiers in Psychology, 8(JAN), 1-11. https://doi.org/10.3389/ fpsyg.2017.02306.

Geiger, S. M., Fischer, D., Schrader, U., \& Grossman, P. (2019a). Meditating for the Planet: Effects of a Mindfulness-Based Intervention on Sustainable Consumption Behaviors. Environment and Behavior, 001391651988089. https://doi.org/10.1177/ 0013916519880897

Geiger, S. M., Grossman, P., \& Schrader, U. (2019b). Mindfulness and sustainability: correlation or causation? Current Opinion in Psychology, 28, 23-27. https://doi.org/10.1016/j.copsyc.2018.09. 010.

Goldberg, S. B., Tucker, R. P., Greene, P. A., Simpson, T. L., Kearney, D. J., \& Davidson, R. J. (2017). Is mindfulness research methodology improving over time? A systematic review. PLoS ONE, 12(10), 1-16. https://doi.org/10.1371/journal.pone.0187298.

Goleman, D., \& Davidson, R. J. (2017). Altered Traits: Science Reveals How Meditation Changes Your Mind, Brain, and Body.

Goyal, M., Singh, S., Sibinga, E. M. S., Gould, N. F., Rowland-Seymour, A., Sharma, R., et al. (2014). Meditation programs for psychological stress and well-being: A systematic review and meta-analysis. JAMA Internal Medicine, 174(3), 357-368. https://doi.org/10. 1001/jamainternmed.2013.13018.

Grabow, M., Bryan, T., Checovich, M. M., Converse, A. K., Middlecamp, C., Mooney, M., et al. (2018). Mindfulness and climate change action: A feasibility study. Sustainability (Switzerland), 10(5), 1-24. https://doi.org/10.3390/su10051508.

Grossman, P. (2008). On measuring mindfulness in psychosomatic and psychological research. Journal of Psychosomatic Research, 64, 405-408. https://doi.org/10.1177/145749690809700216.

Grossman, P. (2011). Defining Mindfulness by How Poorly I Think I Pay Attention During Everyday Awareness and Other Intractable Problems for Psychology's (Re)Invention of Mindfulness:
Comment on Brown et al. (2011). Psychological Assessment, 23(4), 1034-1040. https://doi.org/10.1037/a0022713.

Haddaway, N. R., Woodcock, P., Macura, B., \& Collins, A. (2015). Making literature reviews more reliable through application of lessons from systematic reviews. Conservation Biology, 29(6), 15961605. https://doi.org/10.1111/cobi.12541.

Hamann, G., \& Ivtzan, I. (2016). 30 Minutes in Nature a Day Can Increase Mood, Well-Being, Meaning in Life and Mindfulness: Effects of a Pilot Programme. Social Inquiry IntoWell-Being, 2(2), 34 -46. https://doi.org/10.13165/SIIW-16-2-2-04.

Hanh, T. N. (2013). Love Letter to the Earth. Berkely California: Parallax Press.

Hanley, A. W., Baker, A. K., \& Garland, E. L. (2017). Self-interest may not be entirely in the interest of the self: Association between selflessness, dispositional mindfulness and psychological well-being. Personality and Individual Differences, 117, 166-171. https://doi. org/10.1016/j.paid.2017.05.045.

Hardin, G. (1968). The Tragedy of the Commons. Science, 162(3859), 1243-1248. https://doi.org/10.1126/science.162.3859.1243.

Hart, R., Ivtzan, I., \& Hart, D. (2013). Mind the gap in mindfulness research: A comparative account of the leading schools of thought. Review of General Psychology, 17(4), 453-466. https://doi.org/10. 1037/a0035212.

Harzing, A. W., \& Alakangas, S. (2016). Google Scholar, Scopus and the Web of Science: a longitudinal and cross-disciplinary comparison. Scientometrics, 106(2), 787-804. https://doi.org/10.1007/s11192015-1798-9.

Hedlund-de Witt, A., de Boer, J., \& Boersema, J. J. (2014). Exploring inner and outer worlds: A quantitative study of worldviews, environmental attitudes, and sustainable lifestyles. Journal of Environmental Psychology. https://doi.org/10.1016/j.jenvp.2013. 11.005 .

Helm, S., \& Subramaniam, B. (2019). Exploring socio-cognitive mindfulness in the context of sustainable consumption. Sustainability (Switzerland), 11(13). https://doi.org/10.3390/su11133692.

Hildebrandt, L. K., McCall, C., \& Singer, T. (2017). Differential Effects of Attention-, Compassion-, and Socio-Cognitively Based Mental Practices on Self-Reports of Mindfulness and Compassion. Mindfulness, 8(6), 1488-1512. https://doi.org/10.1007/s12671017-0716-z.

HM Treasury. (2020a). Magenta Book: Central Government guidance on evaluation. Retrieved from http://www.hm-treasury.gov.uk/data magentabook_index.htm. Accessed 10 Apr 2020.

HM Treasury. (2020b). Magenta Book Supplementary Guide: Handling Complexity in Policy Evaluation.

Hölzel, B. K., Lazar, S. W., Gard, T., Schuman-Olivier, Z., Vago, D. R., \& Ott, U. (2011). How does mindfulness meditation work? Proposing mechanisms of action from a conceptual and neural perspective. Perspectives on Psychological Science, 6(6), 537-559. https://doi.org/10.1177/1745691611419671.

Howell, A. J., Dopko, R. L., Passmore, H. A., \& Buro, K. (2011). Nature connectedness: Associations with well-being and mindfulness. Personality and Individual Differences, 51(2), 166-171. https:// doi.org/10.1016/j.paid.2011.03.037.

Hunecke, M., \& Richter, N. (2019). Mindfulness, Construction of Meaning, and Sustainable Food Consumption. Mindfulness, 10(3), 446-458. https://doi.org/10.1007/s12671-018-0986-0.

Ives, C. D., Freeth, R., \& Fischer, J. (2019). Inside-out sustainability: The neglect of inner worlds. Ambio. https://doi.org/10.1007/s13280019-01187-w.

Jacob, J. C., \& Brinkerhoff, M. B. (1999). Mindfulness and Subjective Well-Being in the Sustainability Movement: A Further Elaboration of Multiple Discrepancies Theory. Social Indicators Research, 341368.

Jacob, J., Jovic, E., \& Brinkerhoff, M. B. (2009). Personal and planetary well-being: Mindfulness meditation, pro-environmental behavior 
and personal quality of life in a survey from the social justice and ecological sustainability movement. Social Indicators Research, 93(2), 275-294. https://doi.org/10.1007/s11205-008-9308-6.

Kabat-Zinn, J. (2003). Mindfulness-based interventions in context: Past, present, and future. Clinical Psychology: Science and Practice, 10(2), 144-156. https://doi.org/10.1093/clipsy/bpg016.

Kabat-Zinn, J. (2017). Too Early to Tell: The Potential Impact and Challenges-Ethical and Otherwise-Inherent in the Mainstreaming of Dharma in an Increasingly Dystopian World. Mindfulness, 8(5), 1125-1135. https://doi.org/10.1007/s12671017-0758-2.

Kaiser, F. G., \& Wilson, M. (2004). Goal-directed conservation behavior: The specific composition of a general performance. Personality and Individual Differences, 36(7), 1531-1544. https://doi.org/10.1016/j. paid.2003.06.003.

Kantowitz, B. H., Roediger, H. L., \& Elmes, D. G. (2015). Experimental psychology. Boston, MA: Cengage Learning.

Kasser, T. (2017). Living both well and sustainably: A review of the literature, with some reflections on future research, interventions and policy. Philosophical Transactions of the Royal Society A: Mathematical, Physical and Engineering Sciences, 375(2095). https://doi.org/10.1098/rsta.2016.0369.

Keng, S. L., Smoski, M. J., \& Robins, C. J. (2011). Effects of mindfulness on psychological health: A review of empirical studies. Clinical Psychology Review, 31(6), 1041-1056. https://doi.org/10.1016/j. cpr.2011.04.006.

Kiken, L. G., Garland, E. L., Bluth, K., Palsson, O. S., \& Gaylord, S. A. (2015). From a state to a trait: Trajectories of state mindfulness in meditation during intervention predict changes in trait mindfulness. Personality and Individual Differences, 81, 41-46. https://doi.org/ 10.1016/j.paid.2014.12.044.

Klöckner, C. A., \& Verplanken, B. (2019). Yesterday's Habits Preventing Change for Tomorrow? About the Influence of Automaticity on Environmental Behaviour. In L. Steg, A. van de Berg, \& J. I. M. de Groot (Eds.), Environmental Psychology (pp. 238-250). https://doi.org/10.1002/9781119241072.ch24.

Kollmuss, A., \& Agyeman, J. (2002). Mind the Gap: Why do people act environmentally and what are the barriers to pro-environmental behavior? Environmental Education Research, 8(3), 239-260. https:// doi.org/10.1080/13504620220145401.

Kormos, C., \& Gifford, R. (2014). The validity of self-report measures of proenvironmental behavior: A meta-analytic review. Journal of Environmental Psychology, 40, 359-371. https://doi.org/10.1016/j. jenvp.2014.09.003.

Kreplin, U., Farias, M., \& Brazil, I. A. (2018). The limited prosocial effects of meditation: A systematic review and meta-analysis. Nature Scientific Reports, 8(1), 1-10. https://doi.org/10.1038/ s41598-018-20299-z.

Lange, F., \& Dewitte, S. (2019). Measuring pro-environmental behavior: Review and recommendations. Journal of Environmental Psychology, 63(April), 92-100. https://doi.org/10.1016/j.jenvp. 2019.04.009.

Lange, F., Steinke, A., \& Dewitte, S. (2018). The Pro-Environmental Behavior Task: A laboratory measure of actual pro-environmental behavior. Journal of Environmental Psychology, 56, 46-54. https:// doi.org/10.1016/j.jenvp.2018.02.007.

Levitt, H. M., Creswell, J. W., Josselson, R., Bamberg, M., Frost, D. M., \& Suarez-Orozco, C. (2018). Journal article reporting standards for qualitative research in psychology: The APA Publications and Communications Board task force report. American Psychologist, 73(1), 26-46. https://doi.org/10.1037/amp0000191.

Livingstone, L. (2019). Taking Sustainability to Heart - Towards Engaging with Sustainability Issues Through Heart-Centred Thinking. Sustainability and the Humanities, 2018, 455-468.

Loy, L. S., \& Reese, G. (2019). Hype and hope? Mind-body practice predicts pro-environmental engagement through global identity.
Journal of Environmental Psychology, 66(August), 101340. https://doi.org/10.1016/j.jenvp.2019.101340.

Mäkiniemi, J.-P., \& Heikkilä-Tammi, K. (2018). Promoting Sustainability: The Effects of Workplace Mindfulness Training. Electronic Journal of Business Ethics and Organization Studies, 23(1).

MAPPG. (2015). Mindful Nation UK.

McCall, C., Steinbeis, N., Ricard, M., \& Singer, T. (2014). Compassion meditators show less anger, less punishment, and more compensation of victims in response to fairness violations. Frontiers in Behavioral Neuroscience, 8(DEC), 1-10. https://doi.org/10.3389/ fnbeh.2014.00424.

Medvedev, O. N., Bergomi, C., Röthlin, P., \& Krägeloh, C. U. (2018). Assessing the Psychometric Properties of the Comprehensive Inventory of Mindfulness Experiences (CHIME) Using Rasch Analysis. European Journal of Psychological Assessment. https:// doi.org/10.1027/1015-5759/a000453.

Milne, G. R., Villarroel, F., \& Kaplan, B. (2019). Mindful consumption: Three consumer segment views. Australasian Marketing Journal (AMJ), (xxxx). https://doi.org/10.1016/j.ausmj.2019.09.003.

Ndubisi, N. O., Nygaard, A., \& Capel, C. (2019). Mindfulness-based business strategies and the environment. Business Strategy and the Environment, 433-435. https://doi.org/10.1002/bse.2218.

Neff, K. D., Kirkpatrick, K. L., \& Rude, S. S. (2007). Self-compassion and adaptive psychological functioning. Journal of Research in Personality, 41(1), 139-154. https://doi.org/10.1016/j.jrp.2006.03. 004.

O'Brien, K. L. (2016). Climate change and social transformations: is it time for a quantum leap? Wiley Interdisciplinary Reviews: Climate Change, 7(5), 618-626. https://doi.org/10.1002/wcc.413.

O'Brien, K. (2018). Is the $1.5^{\circ} \mathrm{C}$ target possible? Exploring the three spheres of transformation. Current Opinion in Environmental Sustainability, 31, 153-160. https://doi.org/10.1016/j.cosust.2018. 04.010.

Pandey, A., Chandwani, R., \& Navare, A. (2018). How can mindfulness enhance moral reasoning? An examination using business school students. Business Ethics, 27(1), 56-71. https://doi.org/10.1111/ beer.12171.

Panno, A., Giacomantonio, M., Carrus, G., Maricchiolo, F., Pirchio, S., \& Mannetti, L. (2018). Mindfulness, Pro-environmental Behavior, and Belief in Climate Change: The Mediating Role of Social Dominance. Environment and Behavior, 50(8), 864-888. https:// doi.org/10.1177/0013916517718887.

Park, H. J., \& Dhandra, T. K. (2017). Relation between dispositional mindfulness and impulsive buying tendency: Role of trait emotional intelligence. Personality and Individual Differences, 105, 208-212. https://doi.org/10.1016/j.paid.2016.09.061.

Patel, T., \& Holm, M. (2018). Practicing mindfulness as a means for enhancing workplace pro-environmental behaviors among managers. Journal of Environmental Planning and Management, 61(13), 2231-2256. https://doi.org/10.1080/09640568.2017. 1394819.

Pfattheicher, S., Sassenrath, C., \& Schindler, S. (2016). Feelings for the Suffering of Others and the Environment: Compassion Fosters Proenvironmental Tendencies. Environment and Behavior, 48(7), 929-945. https://doi.org/10.1177/0013916515574549.

Purser, R. (2019). Moving mindfulness from "me" to "we." Retrieved July 15, 2019, from OpenDemocra website: https://www. opendemocracy.net/en/transformation/civic-mindfulness/

Pykett, J., Howell, R., Lilley, R., Jones, R., \& Whitehead, M. (2016). Chapter 5: Governing mindfully. In Emotional States: Sites and spaces of affective governance.

Richter, N., \& Hunecke, M. (2020). Facets of Mindfulness in Stages of Behavior Change Toward Organic Food Consumption. Mindfulness. https://doi.org/10.1007/s12671-020-01351-4. 
Rosenberg, E. L. (2004). Mindfulness and consumerism. In T. Kasser (Ed.), Psychology and consumer culture: The struggle for a good life in a materialistic world (pp. 107-125). https://doi.org/10.1037/ 10658-007.

Ruedy, N. E., \& Schweitzer, M. E. (2010). In the Moment: The Effect of Mindfulness on Ethical Decision Making. Source Journal of Business Ethics Journal of Business Ethics, 95(95), 7373-7387. https://doi.org/10.1007/s10551-011-0796-y.

Ryan, R. M., \& Deci, E. L. (2008). A self-determination theory approach to psychotherapy: The motivational basis for effective change. Canadian Psychology, 49(3), 186-193. https://doi.org/10.1037/ a0012753.

Ryan, R. M., Huta, V., \& Deci, E. L. (2008). Living well: A self-determination theory perspective on eudaimonia. Journal of Happiness Studies, 9(1), 139-170. https://doi.org/10.1007/s10902-006-9023-4.

Sajjad, A., \& Shahbaz, W. (2020). Mindfulness and Social Sustainability: An Integrative Review. Social Indicators Research, 0123456789. https://doi.org/10.1007/s11205-020-02297-9.

Schmidt, A. T. (2016). The ethics and politics of mindfulness-based interventions. Journal of Medical Ethics, 42(7), 450-454. https://doi. org/10.1136/medethics-2015-102942.

Schutte, N. S., \& Malouff, J. M. (2018). Mindfulness and connectedness to nature: A meta-analytic investigation. Personality and Individual Differences, 127(February), 10-14. https://doi.org/10.1016/j.paid. 2018.01.034.

Sevinc, G., \& Lazar, S. W. (2019). How does mindfulness training improve moral cognition: a theoretical and experimental framework for the study of embodied ethics. Current Opinion in Psychology, 28, 268-272. `https://doi.org/10.1016/j.copsyc.2019.02.006.

Shapiro, S. L., Carlson, L. E., Astin, J. A., \& Freedman, B. (2006). Mechanisms of mindfulness. Journal of Clinical Psychology, 62(3), 373-386. https://doi.org/10.1002/jclp.20237.

Shapiro, S. L., Jazaieri, H., \& Goldin, P. R. (2012). Mindfulness-based stress reduction effects on moral reasoning and decision making. The Journal of Positive Psychology, 7(6), 504-515. https://doi.org/ 10.1080/17439760.2012.723732.

Shapiro, S., Siegel, R., \& Neff, K. D. (2018). Paradoxes of Mindfulness. Mindfulness, 9(6), 1693-1701. https://doi.org/10.1007/s12671-0180957-5.

Sheate, W., Twigger-Ross, C., Papadopoulou, L., Sadauskis, R., White, O., Orr, P., ... Eales, R. (2016). Learning lessons for evaluating complexity at the nexus. 1-99. Retrieved from https://www.cecan. ac.uk/resources. Accessed 10 Apr 2020.

Singer, T., \& Engert, V. (2019). It matters what you practice: differential training effects on subjective experience, behavior, brain and body in the ReSource Project. Current Opinion in Psychology, 28, 151158. https://doi.org/10.1016/j.copsyc.2018.12.005.

Siqueira, R. P., \& Pitassi, C. (2016). Sustainability-oriented innovations: Can mindfulness make a difference? Journal of Cleaner Production, 139, 1181-1190. https://doi.org/10.1016/j.jclepro.2016.08.056.

Stanszus, L. S., Fischer, D., Böhme, T., Frank, P., Fritzsche, J., Geiger, S., et al. (2017). Education for Sustainable Consumption through Mindfulness Training: Development of a Consumption-Specific Intervention. Journal of Teacher Education for Sustainability, 19(1), 5-21. https://doi.org/10.1515/jtes-2017-0001.

Stanszus, L. S., Frank, P., \& Geiger, S. M. (2019). Healthy eating and sustainable nutrition through mindfulness? Mixed method results of a controlled intervention study. Appetite, 141(June), 104325. https:// doi.org/10.1016/j.appet.2019.104325.

Steg, L. (2016). Values, Norms, and Intrinsic Motivation to Act Proenvironmentally. Annual Review of Environment and Resources, 41(1), 277-292. https://doi.org/10.1146/annurevenviron-110615-085947.

Steg, L., \& Vlek, C. (2009). Encouraging pro-environmental behaviour: An integrative review and research agenda. Journal of
Environmental Psychology, 29(3), 309-317. https://doi.org/10. 1016/j.jenvp.2008.10.004.

Swim, J. K., Clayton, S., \& Howard, G. S. (2011). Human Behavioral Contributions to Climate Change: Psychological and Contextual Drivers. American Psychologist, 66(4), 251-264. https://doi.org/ 10.1037/a0023472.

Tam, K. P. (2013). Dispositional empathy with nature. Journal of Environmental Psychology, 35, 92-104. https://doi.org/10.1016/j. jenvp.2013.05.004.

Tang, Y. Y., Hölzel, B. K., \& Posner, M. I. (2015). The neuroscience of mindfulness meditation. Nature Reviews Neuroscience, 16(4), 213 225. https://doi.org/10.1038/nrn3916.

Tang, Y., Geng, L., Schultz, P. W., Zhou, K., \& Xiang, P. (2017). The effects of mindful learning on pro-environmental behavior: A selfexpansion perspective. Consciousness and Cognition, 51, 140-148. https://doi.org/10.1016/j.concog.2017.03.005.

Thiermann, U. B., \& Sheate, W. R. (2020). Motivating individuals for social transition: The 2-pathway model and experiential strategies for pro-environmental behaviour. Ecological Economics, 174, 106668. https://doi.org/10.1016/j.ecolecon.2020.106668.

Trautwein, F.-M., Kanske, P., Böckler, A., \& Singer, T. (2020). Differential benefits of mental training types for attention, compassion, and theory of mind. Cognition, 194(July 2019), 104039. https://doi.org/10.1016/j.cognition.2019.104039.

Unsworth, S., Palicki, S. K., \& Lustig, J. (2016). The Impact of Mindful Meditation in Nature on Self-Nature Interconnectedness. Mindfulness, 7(5), 1052-1060. https://doi.org/10.1007/s12671016-0542-8.

Vago, D. R., \& Silbersweig, D. A. (2012). Self-awareness, self-regulation, and self-transcendence (S-ART): A framework for understanding the neurobiological mechanisms of mindfulness. Frontiers in Human Neuroscience, 6(OCTOBER 2012), 1-30. https://doi.org/ 10.3389/fnhum.2012.00296.

Valk, S. L., Bernhardt, B. C., Trautwein, F. M., Böckler, A., Kanske, P., Guizard, N., et al. (2017). Structural plasticity of the social brain: Differential change after socio-affective and cognitive mental training. Science Advances, 3(10), 1-11. https://doi.org/10.1126/sciadv. 1700489.

Van Dam, N. T., van Vugt, M. K., Vago, D. R., Schmalzl, L., Saron, C. D., Olendzki, A., et al. (2018). Mind the Hype: A Critical Evaluation and Prescriptive Agenda for Research on Mindfulness and Meditation. Perspectives on Psychological Science, 13(1), 36-61. https://doi.org/10.1177/1745691617709589.

Van der Werff, E., Steg, L., \& Keizer, K. (2013). It is a moral issue: The relationship between environmental self-identity, obligation-based intrinsic motivation and pro-environmental behaviour. Global Environmental Change, 23(5), 1258-1265. https://doi.org/10. 1016/j.gloenvcha.2013.07.018.

Venhoeven, L. A., Bolderdijk, J. W., \& Steg, L. (2013). Explaining the paradox: How pro-environmental behaviour can both thwart and foster well-being. Sustainability (Switzerland), 5(4), 1372-1386. https://doi.org/10.3390/su5041372.

Vihari, N. S., \& Rao, M. K. (2017). Business model innovation and organisational mindfulness as determinants of corporate sustainability: An empirical study. International Journal of Business Innovation and Research. https://doi.org/10.1504/IJBIR.2017. 083541.

von Borgstede, C., Johansson, L.-O., \& Nilsson, A. (2018). Social Dilemmas: Motivational, Individual, and Structural Aspects Influencing Cooperation. In L. Steg, A. van de Berg, \& J. I. M. de Groot (Eds.), Environmental Psychology (Second edi ed., pp. 207216). https://doi.org/10.1002/9781119241072.ch21.

Von Essen, E., \& Mårtensson, F. (2014). Young adults' use of food as a self-therapeutic intervention. International Journal of Qualitative Studies on Health and Well-Being, 9(1). https://doi.org/10.3402/ qhw.v9.23000. 
Walsh, Z. (2016). A Meta-Critique of Mindfulness Critiques: From McMindfulness to Critical Mindfulness. In R. P, R. P, D. F, \& A. B (Eds.), Handbook of Mindfulness. Mindfulness in Behavioral Health (pp. 153-166). https://doi.org/10.1007/978-3-319-44019411.

Wamsler, C. (2018). Mind the gap: The role of mindfulness in adapting to increasing risk and climate change. Sustainability Science, 13(4), 1121-1135. https://doi.org/10.1007/s11625-017-0524-3.

Wamsler, C. (2019). Contemplative Sustainable Futures: The Role of Individual Inner Dimensions and Transformation in Sustainability Research and Education. In W. Leal, F. Adriana, \& C. Mccrea (Eds.), Sustainability and the Humanities (pp. 359-373). https:// doi.org/10.1007/978-3-319-95336-6.

Wamsler, C. (2020). Education for sustainability: Fostering a more conscious society and transformation towards sustainability. International Journal of Sustainability in Higher Education, 21(1), 112-130. https://doi.org/10.1108/IJSHE-04-2019-0152.

Wamsler, C., \& Brink, E. (2018). Mindsets for Sustainability: Exploring the Link Between Mindfulness and Sustainable Climate Adaptation. Ecological Economics, 151(November 2017), 55-61. https://doi. org/10.1016/j.ecolecon.2018.04.029.

Wamsler, C., Brossmann, J., Hendersson, H., Kristjansdottir, R., McDonald, C., \& Scarampi, P. (2017). Mindfulness in sustainability science, practice, and teaching. Sustainability Science, 1-20. https:// doi.org/10.1007/s11625-017-0428-2.

Wang, X., Geng, L., Zhou, K., Ye, L., \& Ma, Y. (2016). Mindful learning can promote connectedness to nature: Implicit and explicit evidence.
Consciousness and Cognition, 44, 1-7. https://doi.org/10.1016/j. concog.2016.06.006.

Wang, J., Geng, L., Schultz, P. W., \& Zhou, K. (2019). Mindfulness Increases the Belief in Climate Change: The Mediating Role of Connectedness With Nature. Environment and Behavior, 51(1), 3 23. https://doi.org/10.1177/0013916517738036.

Weisbaum, E. (2017). Thich Nhat Hanh 1926. Key Thinkers on The Environment, 268-272. https://doi.org/10.4324/978131554365948.

Werner, A., Spiller, A., \& Meyerding, S. G. H. (2020). The yoga of sustainable diets : Exploring consumers mind and spirit. Journal of Cleaner Production, 243, 118473. https://doi.org/10.1016/j. jclepro.2019.118473.

Whitburn, J., Linklater, W., \& Abrahamse, W. (2019). Meta-analysis of human connection to nature and proenvironmental behavior. Conservation Biology, 1-31. https://doi.org/10.1111/cobi.13381.

Zylstra, M. J., Knight, A. T., Esler, K. J., \& Le Grange, L. L. L. (2014). Connectedness as a Core Conservation Concern: An Interdisciplinary Review of Theory and a Call for Practice. Springer Science Reviews, 2(1-2), 119-143. https://doi.org/10. 1007/s40362-014-0021-3.

Publisher's Note Springer Nature remains neutral with regard to jurisdictional claims in published maps and institutional affiliations. 